\title{
EFFECT OF MECHANICAL DISCONTINUITIES ON THE STRENGTH OF POLYCRYSTALL INE ALUMINUM OXIDE
}

$$
\begin{aligned}
& \text { Jay S. Wailace } \\
& \text { (M. S. thesis) }
\end{aligned}
$$

September 1978

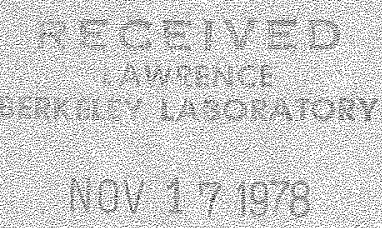

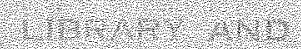

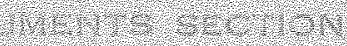

Prepared for the U. S. Department of Energy under Contract W-7405-ENG-48

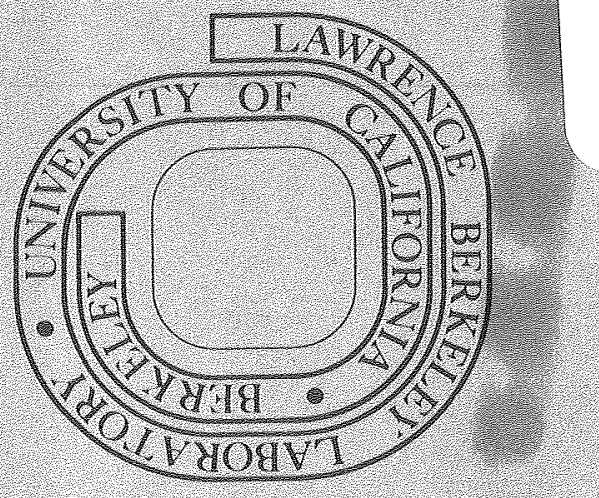

\section{TWO-WEEK LOAN COPY}

This is a Library Circulating Copy which may be borrowed for two weeks. For a personal retention copy, call Tech. Info. Díuision, Ext. 6782 


\section{LEGAL NOTICE}

This report was prepared as an account of work sponsored by the United States Government. Nelther the United States nor the Department of Energy, nor any of their employees, nor any of their coniractors, subcontractors, or their employees, makes any warranty, express or implied, or assumes any legal liability or responsibility tor the accuracy completeness or usefulness of aly information, apparatus, product or process disclosed, or represents that its use would not infinge privately owned rights.

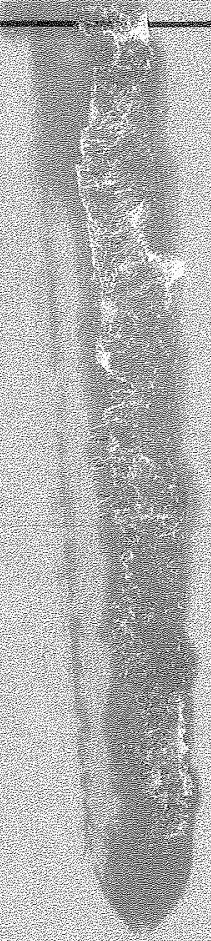




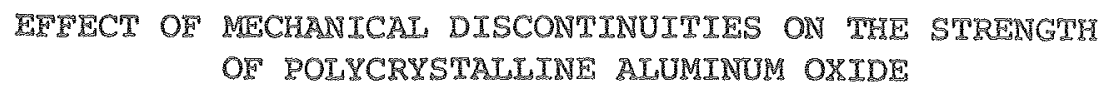

\author{
Jay 5. WaL1ace \\ Lawrence Berkeley Laborabory \\ Univexity of California \\ Berkeley; Calisornia 94720
}

\begin{abstract}
This study examines the efect of antricially introduced spherical voids on the bend strength of a polycrystaline brittle solid and compares the results to traditional empirical and phenomenological poxositystrength relationships. No cosselation is found between these relation ships and the data.

The statistical approach by weibul is examined paxticulardy with regard to the implications to microstructural features. A direct test of Weibull statistics showed deviations from theory pexhaps due to the very small stressed volumes employed. Micxostructural evidence suggests that sone of the basic assumptions in Wedoul's pormulation may restrict its use in this and pexhaps othex systems. Based on the similarity between McClintock"s Statistical model and the observed microstructuxal features a falure critexion for systems with randoniy distributed Flaws is proposed.
\end{abstract}





\section{INTRODUCTION}

In order for matexials to be utilized to theix fullest extent and greatest efficiency, correlations between microstructure and properties must be developed. Several microstructural features have been noted which afect the mechanical properties, such as, strength and fracture toughness, of brittle materials. These features include, but axe by no means limited to, grain size, surface finish, microcxacking and second phases. To date little analytical work has been perfomed relating these microstructural features to mechanical properties: most relationships have been empirical, based on bulk properties such as average grain size, mean surface finish and total second phase content.

Whis study is concerned with the effect of mechanical discontinuities on the fracture strength of a brittle solid. If it is assumed that the body fails from one of these introduced mechanical discontinuities, we must accurately describe the most severe flaw if we are to detemine it's effect on the strength. A thorough description of the most severe Elaw necessarily involves its location, shape, orientation and stress Eield. Because the scope of this work does not allow the time to accurately describe all of these quantities for the most general case, it is necessary to exercise caution when choosing a system for study: for this reason we have chosen to study the effects of axtificially introduced, randomly distributed, spherical yoids on the Eracture strength of polycrystalline aluminum oxide (alumina). The vaxiables for this system are then reduced to sizemdistribution and numbex of discontinuities. 
Alumina was chosen as the matriz matexial for a variety of reasons. First, it is one of the most important commexcial industrial ceramic materials. Second, a wealth of data exists on porosity- Exacture strength relationships of commercial puxity alumina. Finally, previous work in this laboratory has shown that it is possible to consistently sinter high purity alumina powder to $990^{t} 8$ of theoretical density.

The areas in which this study diffex from most previous work are in the production of voids (porosity) and purity (particularly glass phase content) of the material. Other studies have varied porosity content, as well as other microstructural features, by varying the sintering conditions. Because variations in sintering conditions change pore size- and shape-distribution as well as grain and impurity size distribution and shape, it is difficult to make an accurate evaluation of the effect of void content. Also, much of the previous materials studied had a large content $(1-58)$ of glassy-phase distributed along the grain boundaries. This is particularly damaging to the results since the fracture path is often intergranular rather than transgranulax.

In this study the starting powder and processing conditions were identical for each specimen. Spherical voids were produced by mixing a size-separated spherical organic powder with an Mgo-doped alumina starting powder, pressing, then heating the resulting green compact to burn out the organic spheres. All green compacts were then fired under identical conditions.

Four hypotheses will be proposed in section 3 to describe the fracture strength data of these specimens. The data will be presented in section 4 and compared to the hypotheses. 


\section{PROCEDURE}

An organic material was used to produce the voids in the green compact. The following requirements were placed on the organic powder to be used in this study:

1. spherical particles

2. appreciable size fxaction between $25 \mu \mathrm{m}$ and $125 \mu \mathrm{m}$

3. decomposes or vaporizes below $1100^{\circ} \mathrm{C}$ in aix

4. very low residue upon heating.

On the basis of these requirements a readily available mounting powdex, Koldmount, was chosen. Thermogravimetric analysis showed that the powdex burned out of a green compact at $600^{\circ} \mathrm{C}$ and had a $0.025 \%$ residue after heating to $900^{\circ} \mathrm{C}$ for 8 hours.

The organic powder was size separated in a sonic sifter using 37, 44, 63, 74, 105 and $125 \mu \mathrm{m}$ screens. Due to electrostatic charge build-up and screen clogging all powder was screened three times before use.

The alumina powder was prepared (Fig. 2.1) by mixing 0.1 w/o MgO (as $\mathrm{Mg}\left(\mathrm{MO}_{3}\right)_{2}{ }^{\circ} 6 \mathrm{H}_{2} \mathrm{O}$, Mallinckrodt lot $\mathrm{xRX}$ ) and 2. w/o gVA binder (Rolysciences, lot 257-8) with an isopropyl alcohol slurry of Linde $A$ alumina powder (lot 511) in a blender for five minutes. The resulting sluxry was stirred and gently heated until a mushy consistency was reached. Final drying was completed in a drying oven at $50^{\circ} \mathrm{C}$. After drying, al1 powdex was screened through a 44 um (325 mesh) screen to break up large aggregates and to aid homogenization. A weighed amount of size separated organic was then added to the prepared alumina powder and thoroughly mixed by vigorous shaking. 
Early results showed that uniform filling of the uniaxial die was necessary to prevent density gradients in the uniaxially compacted specimens that would lead to warpage upon isostatic pressing. To minimize density gradients, the uniasial die was vibrated and evenly filled when loading powder. Aminimum vibration time was used to prevent segregation of alumina powder and organic spheres. Specimens wexe uniaxially pressed at $15 \mathrm{MPa}$ then isostatically pressed by the wet bag method at $175 \mathrm{MPa}$. The resulting green compacts had a green density of $\sim 488$ of theoretical density.

The compacts were calcined at $900^{\circ} \mathrm{C}$ for 8 hours to burn off the organic spheres and the $\mathrm{PVH}$ binder and to decompose the $\mathrm{Mg}^{\left(\mathrm{NO}_{3}\right)_{2}}{ }^{\circ} 6 \mathrm{H}_{2} \mathrm{O}$ to Mgo.

After fuxnace cooling, the compacts were placed on a molybdenum pedestal and transferred to a high vacuum $\left(10^{-6}\right.$ torx) tantalum resistance Brew furnace. The firing schedule was based on previous work ${ }^{15}$ performed in this laboratory which showed that very high density $\left(99^{+}{ }^{+}\right.$) could be obtained. The Eiring schedule mas:

$$
\begin{aligned}
& \text { 1. heat a } 20^{\circ} \mathrm{Cmin}^{-1} \text { to } 1200^{\circ} \mathrm{C} \\
& \text { 2. heat } 2^{\circ} \mathrm{Cmin}^{-1} \text { to } 1750^{\circ} \mathrm{C} \\
& \text { 3. hold } 91750^{\circ} \mathrm{C} \text { for } 1 \text { hour. } \\
& \text { 4. cool } 10^{\circ} \mathrm{Cmin}^{-1} \text { to room tempexature. }
\end{aligned}
$$

All specimens were fired according to this schedule. After firing the density of all specimens was measured by the Archimedes displacement method using distilled water. Void Iractions were calculated Irom the measured density differences between samples without and with introduced voids. 
Fired specimens were mounted on alumina base plates and were sawn to a $1.2 \mathrm{~mm}$ thickness and a width of three (3) masing a resinoid bonded 220 grit diamond blade turning at a rim speed of $\sim 27 \mathrm{~m} / \mathrm{s}$. The specimens wexe fed in the dixection of blade rotation with a constant feed rate of $\sim 10^{-4} \mathrm{~m} / \mathrm{s}$. Flowing kerosene was used as the coolant. Strength measurements were performed on a four point bend tester (Fig. 2.2) at an average loading rate of $4.5 \mathrm{MPa}^{\circ} \mathrm{sec}^{-1}$. The overall span of the four point tester $\left(l_{1}+l_{2}\right)$ was $19.05 \mathrm{~mm}$ and the inner span $\left(\ell_{1}\right)$ was $6.35 \mathrm{~mm}$. Since previous work had shown ${ }^{17}$ that polishing the tensile surface yielded no improvement in fracture strength over the as-cut surfaces, all testing was performed with the tensile surface in the as-cut condition.

After testing, representative samples were prepared for microscopic examination. Fracture surfaces were sputtered with a $200 \AA$ gold coating to prevent charging in the SEM. Polished surfaces were prepared by polishing on $30 \mu \mathrm{m}, 15 \mu \mathrm{m}$ then $6 \mu \mathrm{m}$ diamond bonded wheels before being lapped on $6 \mu \mathrm{m}, 1 \mu \mathrm{m}$ and Einaliy $1 / 4 \mu \mathrm{m}$ diamond impregnated nylon cloths in Syntron polishers. Since no suitable chemical etch was Eound, the specimens were removed from the polishing mounts and thermally etched a $1400^{\circ} \mathrm{C}$ in aix fox four hours. The polished and etched surfaces were then sputtered with a $200 \AA$ gold coating.

Grain size was measured as the mean linear intercept of approximately 400 grains. 


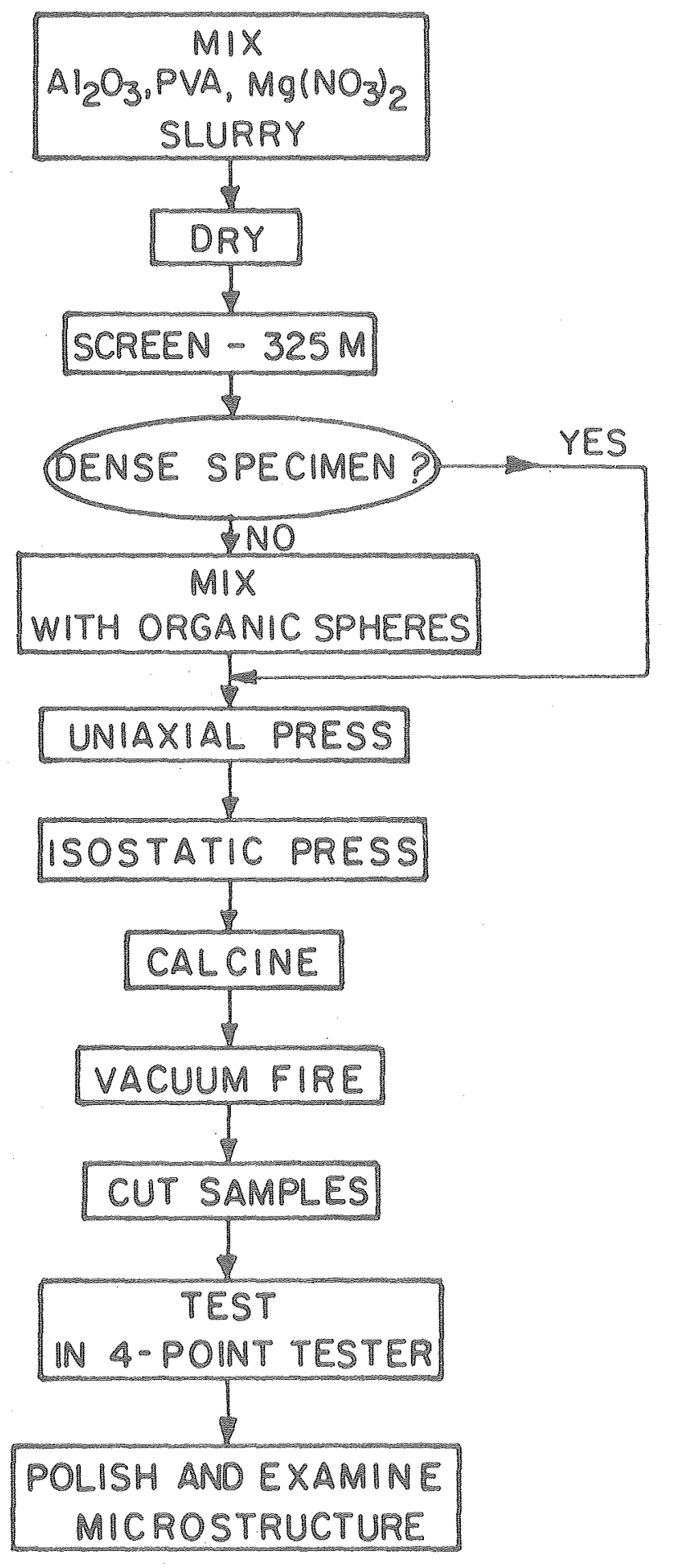

X8L789-5754

FIg。 2.1

Specimen Preparation. 


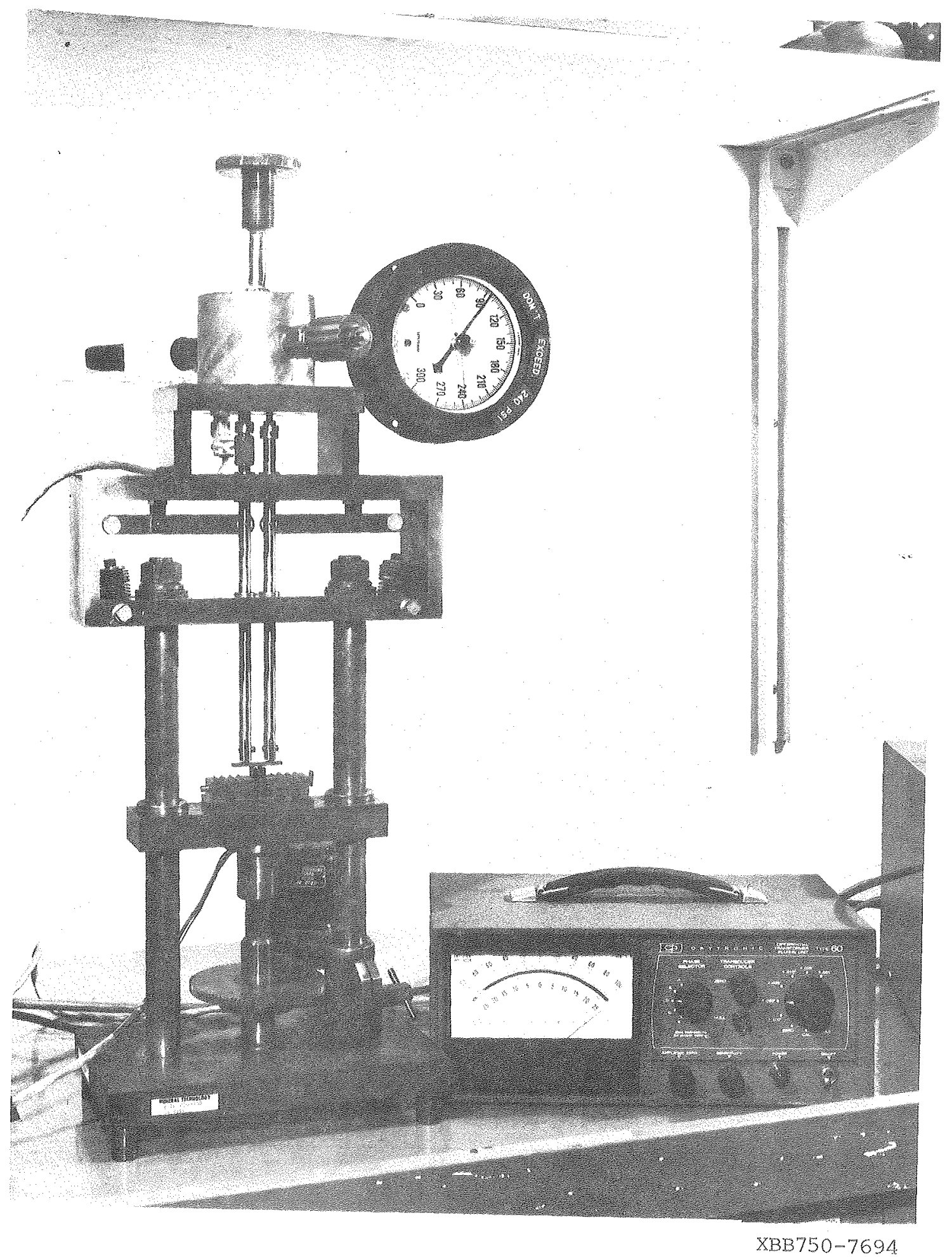

Fig. 2.2 


\section{DEVELOPMENT}

It is intended that this section presents in some coherent manner several hypotheses which could explain the strength data generated in this study. Comparison of model predictions to actual data wil be deferred until section four. However, brief discussion of the implications of each hypothesis will be presented with its development.

In order to place Weibul1's general statistical approach, which is based on weakest link theory, into historical perspective, it is interesting to note that weibul1 first published his theory in 1939. nineteen years after Gxiffith's paper and ten years after development of extreme value theory. For sake of comparison, standardized methods of valuating fracture toughness wexe not published unti1 $1965 .^{11}$ Although the Weibull approach contains some fundamental limitations, ${ }^{9}$ it has provided fit for data up to the present day.

Only with the recent need to develop structural matexials with bettex reliability in high temperature and corrosive environments, such as gas turbines, nualear reactors and coal gasifiers, has work on fracture statistics received more complete attention. Much of the recent work on fracture statistics is based on extreme value statistics with little regard to the microstructure of the material. However, recent work by Mcclintock ${ }^{3}$ and others 9.12 develop fracture statistics from not only statistical theory but also with consideration of the microstructural parameters which can influence the physical properties. Efforts in correlating observed matexial flaws with strength measurements have been aided with recent tabulations of elasticity 
solutions of complex flaw geometries. 13,14

In the development of this section weibul1"s analysis is given the first and the most detailed treatment because of its widespread use and because the approach and methods used by weibull are extended and used as a basis for the othex hypotheses. After development of the Weibull approach possible extensions based on assumptions concerning the nature of the flaws are proposed; elasticity and linear elastic fracture mechanics (LEFM) solutions are utilized. These extensions of the weibull approach are presented in genexal forms so that trends may be predicted. Prediction of absolute values of strength would require much furthex refinement.

\section{The weibull Analysis}

The most universally used method of describing the variations in strength of "identical" specimens was pioneered by Weibull. He reasoned that since strength of a body is dependent upon the severity of the flaw causing failure, as was shown some years earliex by Gxiffith, and that since seemingly identical bodies show significant vaxiations in strength, there must be flaws of varying severity within the body. By assuning that a single severe 5 law propagates to final material failure without interacting with othex flaws, he was able to utilize weakest link theory.

It can be shown by weakest link theory that the probability of survival, $g_{5}$ of a body which fails from a single volumetric flaw is given by:

$$
P_{S}=\exp \left[-\int_{V O I} g(S) \cdot d V\right]
$$


where $g(S)$, the volumetric strength function, is a function of the density and sevexity distributions (size, shape and orientation) of flaws in the volume. Weibul chose a function of the form

$$
g(s)=\left(s / s_{0}\right)^{m}
$$

to describe the volumetric strength distribution and termed the integral over the volume the Risk of Rupture, B:

$$
B=\int_{\mathrm{vol}} g(s) d V=\int_{\text {vol }}\left(S / s_{0}\right)^{m} d v
$$

The probability of survival can then be related to the stress on the sample (S), characteristic strength $\left(S_{0}\right)$ and spread about the characteristic strength (m, the weibull modulus). With this equation Weibull was not only able to accurately descxibe the spread of strengths about a characteristic value for "identical" specimens but could also predict reduction in median strength when specimens of incxeased volume were tested.

The calculation of the Risk of Rupture in specimens tested in four-point bending, Fig. 3.1a, is complicated by the fact that the stress in the specimen is not constant with position in the specimen (Figs. 3.1b, 3.1c). The combination of Elaw severity and applied stress at the rlaw deternines whether the flaw will propagate. Assuning that only the flaws in the tensile regions of the specimen can cause failure, the Risk of Rupture in four-point bending may be written:

$$
B=\frac{w h}{2(m+1)}\left(l_{1}+\frac{l_{2}}{m+1}\right)\left(\frac{S_{\mathrm{TS}}}{S_{0}}\right)^{\mathrm{m}} \text { (Dexivation: Appendix 1) }
$$


For a finite number of specinens, $N$, which are ranked in order

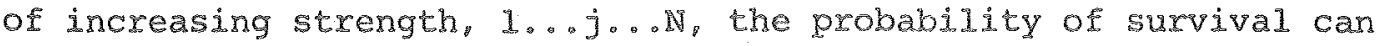
be approximated:

$$
E_{S}=1-\frac{j-0.3}{N+0.4}
$$

Substituting these expressions for $B$ and $P_{S}$ into equation ( 3.1 ) we obtain

$$
1-\frac{j-0.3}{N+0.4}=\exp \left(-\frac{w h}{2(m+i)}\right)\left(l_{1}+\frac{l_{2}}{m+1}\right)\left(\frac{S_{T S}}{S_{0}}\right)^{m}
$$

Taking the natuxal logarith of both sides twice:

$$
\ln \ln \left(\frac{1}{1-\frac{j-0.3}{N+0.4}}\right)=m \ln \left(s_{\mathrm{mS}}\right)+\ln \left[\left(\frac{w h}{2(m+1)}\right)\left(l_{1}+\frac{l_{2}}{m+1}\right)\left(l_{1}+\frac{l_{2}}{m+1}\right)\right] \mathrm{s}_{0}^{-m}
$$

Since this equation is of the form $y=a x+b$, when the experimental values of strength $\left(S_{T S}\right)$ and rank $(j)$ are plotted, the slope of the least squares fit of the data is the weibuli modulus, m. The characteristic strength can be computed from the relationship:

$$
S_{0}=\left[\frac{-\operatorname{sh}\left(l+\frac{2}{1}\right)}{2(m+1) \ln \left(1-\frac{j-0.3}{N+0.4}\right)}\right]^{1 / m} S_{\operatorname{TS}}
$$

For the median strength value, smed"

$$
s_{0}=\left[\frac{w h\left(l_{1}+\frac{\ell_{2}}{m+1}\right)}{1.386(m+1)}\right]^{1 / m} s_{\text {med }}
$$


The Weibull approach places restrictions on the homogeneity of the matexial. It is evident that, if there axe flaws of varying sevexity randomly distributed within the volume, the matexial is not homogeneous on a microscale. However, in oxder to meet weibull's criterion for homogeneity, the material must be homogeneous on a macroscale: the Elaw severity distribution must be random within the material. This leads to an interesting contradiction of weibull's assumption of no flaw-flaw intexaction: if flaws are distributed randomly within the body, there is a finite probability of a flaw existing within the stress field of another flaw. Correcting for this stress field overlap in the Risk of Rupture calculation would be difficult because correction would require expressions for density, size distribution, shape distribution and orientation distribution of the flaws in addition to accurate elasticity solutions describing the stress fields. It must be assumed that interacting flaws are considered as one large flaw.

\section{Introduced Stress pields}

When large numbers of mechanical discontinuities are introduced into the material, modifications must be made to the Risk of Rupture calculation in the Weibull approach because mechanical discontinuities change the stress distribution in the surrounding material.

Vardar et al. ${ }^{1}$ considered the state of stress around a spherical void, as derived by Goodiex, ${ }^{2}$ and corrected the Risk of Rupture calculation for the superimposed stress distribution. Their approach also took into account an increase in the nomiral stress due to reduction of cross-sectional area of the matrix. The Vardar approach assumes 
that the material is homogeneous and that the introduced voids do not change the failure mechanisn or the intrinsic flaws; a reduction in strength is due only to the increased stxess level in the small volume near the voids. It must be emphasized, however, that, due to the statistical nature of flaw size and spatial distribution, the flaw causing failure need not be within the stress field of a void. For this reason the Risk of Rupture calculation also includes a term for the volume of material which sees only the nominal stress. Also, Vardar estimates that complications arising from void stress field overlap, limit his analysis to a void fraction of approximately 0.10. Due to the complexity of the calculations, only the results are quoted here:

$$
B=\left(\frac{S_{T S}}{S_{T S}(0)}\right)^{m} v\left(1+v_{v}\right)^{-m} \quad\left(1-v_{v}{ }^{3}\right)+\frac{3(2 m+1)}{2^{2}} V_{v} H(m)
$$

$F(m)$ and depend upon the choice of limits over which the stress field of the spherical vold is integrated. Because an analytic solution was not possible, the numerical results for the median strength $\left(P_{S}=0.5\right.$ or $\left.B=0.693\right)$ are presented in graphical form for $V=0.20$ (Fig. 3.2).

Several interesting conclusions can be drawn from Vardar's analysis. First, voids are not the cause of failure, pex se, but xathex it is the stress rield of these voids which interacts with intrinsic flaws causing the intrinsic flaws to propagate to inal failure. Second, the reduction in strength is a function of the volume fraction of voids but is independent of void size. Finally, since 
the law population does not change with the introduction of voids, it is expected that the dexivative of the plot of failure stress would be continuous to zero volume fraction of voids: $i . e .$, the fracture stress should not drop discontinuously with the introduction of the first void.

\section{Void-Grain Boundary Interactions}

A possible modification of the Weibull analysis is to assume the nature of the flaws causing failure ox, more precisely, whether the Elaws which cause final failure are associated with any specific microstructural feature. Weibull assumed that flaws were a volume effect and did not directly speculate on their nature. This approach, while useful, would be more informative if it would indicate something about the flaw itself, either in a positive ox negative sense, so that "matexials engineexing" could be performed. That is, if flaws are associated with, say, grain boundaries, then a compromise of the number of grain boundaries (statistical nature of flaw size) and the length of grain boundaries (size of flaws) might be attempted. As another example, Vardar's analysis, if correct, indicates that if we model the pores in a ceranic system as spherical voids, then the strength distribution and median strength are dependent on volume fraction of porosity and not on pore size. From a practical standpoint, processing might then be adjusted so that pores which are detectable by standard nondestrictive examination techniques are produced.

When associating flaws with microstructural features a logical starting point is to assume that flaws are associated with grain 
boundaries. As a precedent MCClintock ${ }^{3}$ assumed that cracks are random aggregations of unbonded grain boundaries. Although the condition that grain boundaries are unbonded may be a bit extreme, the large fraction of intergranular fracture in many ceramic materials indicates that grain boundaries tend to be weaker than the grains themselves. The first approach could be an extension of Vardax's analysis by assuming that the Risk of Rupture is proportional to the numbex of grain boundaries within the stxess field of the void, much as Weibull assumes that the Risk of Rupture is proportional to the volume of stressed material. This would result in equations similar to Vardax's (Eq. 3.9) with a grain size term. For specimens with equal grain size the resulting equation would be identical to vardar's equation in form and in the prediction that there would be no void size dependence.

Another assumption that could be made is that the Risk of Rupture is proportional to the number of grain boundaxies intersecting the void surface. The number of grain boundary-void intersections, ${ }^{\mathrm{G}}$ " $^{\prime}$ can be written:

$$
\mathbb{N}_{G B}=\int_{\text {voids }} \frac{\mathrm{d}^{2}}{\mathrm{G}^{2}}=\int_{V} \mathbb{N}_{\mathrm{v}} \frac{\mathrm{d}^{2}}{\mathrm{G}^{2}} \mathrm{dV}
$$

Substituting for $\mathbb{N}_{\mathrm{y}}$ and integrating we obtain:

$$
V_{G B}=v \frac{6 V}{d G^{2}}
$$


Physical1y. Weibull associated Ilaws with the volume of the specimen. When associating flaws with a specific microstructural feature, ie, the grain boundary-void intexsections, we replace the volume in the Weibull expression by the numbex of these features in the sample:

$$
B=\frac{3 V_{v} W h}{d G^{2}(m+1)}\left(1+\frac{2}{m+1}\right)\left(l_{1}+\frac{2}{m+1}\right)\left(\frac{S_{T S}}{S_{0}}\right)^{m}
$$

Solving for the median stxength we obtain:

$$
S_{\text {med }}=\frac{V_{v} w h}{d G^{2}(m+1)}\left(1+\frac{l_{2}}{m+1}\right)\left(l_{I}+\frac{2}{m+1}\right)^{-1 / m} s_{0}
$$

we must digress here to consider the physical meaning of the characteristic strength. Weibull in his formulation of the Risk of Rupture did not attach a direct meaning to the charactexistic strength other than that as a scale factor for the strengths of different materials. Howevex, when we use the Weibuli formulation to predict the strength of specimens of varying volumes or specimens under varying loading conditions (three point bending, four point bending, uniaxial tension) we have assumed that the characteristic strength is a property of the rnaterial. In addition, Vardar's derivation assumes that the material fails Exom inherent Elaws: therefore the characteristic strength must be a material property independent of the void diameter and volume fraction. Because similar arguments may be used with the Weibul1 Modulus we shall also consider $m$ a material property. thus constant. 
Returning to our previous reasoning, if we assume $G_{,} S_{0}$ and m constant in all specimens, then:

$$
\mathrm{s}_{\text {med }}=\mathrm{C}\left[\frac{\mathrm{d}}{\mathrm{v}_{\mathrm{y}}}\right]^{1 / \mathrm{m}}
$$

and

$$
\ln s_{\text {med }}=\frac{1}{\mathrm{gn}} \ln \left(\frac{\mathrm{d}}{v_{v}}\right)+c
$$

When $\ln s_{\text {med }}$ is plotted against $\ln \left(d / v_{v}\right)$ for each of the void size/void volume fraction sets then a straight line should result with a slope of $\frac{1}{m}$. if the railure occurs at the "weakest" grain boundary-void intersection.

We can make two predictions from this hypothesis. First, the median strength should decrease as the volume fraction of voids increases. Second, for equal volume fractions of voids the large voids should be less detximental to strength than the small voids. Note, it would not be expected that this model would be valid when a poor statistical sampling of grain boundary-void intersections occurs $\left(v_{v} \rightarrow 0\right)$ or when voidmoid interactions occur $\left(v_{v} \geqslant 0.10\right)$ 。 Voids as Flaws

Linear elastic fracture mechanics (LEFM) has been used to predict Elaw size at fracture from the strength data and Ixacture coughness values. However, due to the difficulty of producing accurate flaw sizes and tip sharpness and the difficulty in measuxing these quantities. the prediction of strength fxom measured flaws is performed infrequently. For blunt mechanical discontinuities, such as spherical voids, LEFM solutions are not expected to apply as sharp crack tips are 
necessary. However, in a polycrystalline specimen with many grains on the surface of the void, grain boundary grooving is expected to occur due to the differences in surface energy of the grain-grain interface and the grain-vapor incerface. Thermodynamics predicts that the groove is sharg to atonic dinensions, thexefore, LEFM is expected to apply to even the "blunt" spherical voids if the voids have several grain boundaries exposed on the suxface duxing sintering. Note that flawed ox cracked grain boundaxies, as required by Mcclintock, are not necessary.

If the gross assumption is made that the 2-dimensional IEFM solution for the pennymshaped Ilaw approximates the 3-dimensional case of the spherical void, then:

$$
\sigma_{f}=R_{I C}(X d)^{-1 / 2}=C^{-1 / 2}
$$

Variations in fracture strength then must be related to the variation in the void sizes and the probability of finding a large void in a region of high nominal stress.

When the void densities (statistical sampling) and volumes of specimens are equal, then the median Exacture strengths of groups of samples should be related by:

$$
\frac{s_{\text {med } I}}{s_{\text {med } 2}}=\left(\frac{d_{2}}{d_{1}}\right)^{1 / 2}
$$

when

$$
\mathbb{N}_{v_{1}}=\mathbb{N}_{v_{2}}
$$


or:

$$
\left(\frac{v_{1}}{v_{v_{2}}}\right)^{1 / 3}=\frac{a_{1}}{a_{2}}
$$

Substituting equation (3.19) into equation (3.13) we obtain:

$$
\frac{s_{\text {med } 1}}{s_{\text {med 2 }}}=\left(\frac{v_{2}}{v_{v_{1}}}\right)^{1 / 6}
$$

In addition, the ratio of the strongest to weakest specimens in a group would necessarily be less than or equal to the square root of the ratio of the smallest to largest void sizes:

$$
\frac{s_{T S \max }}{S_{T S} \min } \leqslant\left(\frac{a_{\text {min }}}{d_{\text {max }}}\right)^{1 / 2}
$$

This hypothesis predicts a definite stxength dependence on the void diameter but predicts very slight influence of changes in void Exaction.

\section{Flaw-Flaw Interaction}

As first noted by Weibul1. statistical strength theories place restrictions on the homogeneity of the material: flaw-flaw interactions are assumed to not occur. Due to the statistical nature of flaw size, shape, oxientation and distribution and the complexity of stress distribution around complex flaw shapes there is little hope of accurately predicting the effect of flaw-flaw interaction on the strength of brittle solids. 
Pexhaps the simplest case of Ilaw flaw interaction is one of sphexical voids randomly distributed in a matxix. For this case the stress distribution around isolated voids is known, as are obviously, size, shape and spatial distribution of voids. If the voids are distributed randomly, we would expect clustexing of voids thus changes in the stress field. Now, even in this least difficult solution we must determine the following:

1. Probabilities of $1,2,3 \ldots$ voids clustering

2. Rrobability of shapes occurring, ie, void-void orientations

3. Probability of cluster oxientations

4. Stress fields acound clusters of $1,2,3, \ldots, n$ voids.

Since each of these four calculations is formidable and beyond the scope of this work, a more general approach will be taken.

It can be shown that the probability of a cluster of n voids depends on the void density (number pex unit volume, $\mathbb{N}_{V}$ ) and that equal void densities have equal probabilities for a cluster of in voids. Equal void densities occur when the relation

$$
\left(\frac{v_{1}}{v_{v_{2}}}\right)^{1 / 3}=\frac{d_{1}}{a_{2}}
$$

is satisfied. Furthemore, the physical dimension which describes the flaw size, $a_{\text {, }}$ is proportional to the diameter of the voids occurxing in the cluster. From LEFM the fracture stress can then be given:

$$
\sigma_{I}=K_{I C}\left(X_{a}\right)^{-1 / 2}=C(d)^{-1 / 2}
$$

where $Y$ is a flaw shape and orientation factor. If we compare median strengths and combine equations (3.19) and (3.17), we obtain: 


$$
\frac{s_{\text {med }}}{s_{\text {med }_{2}}}=\left(\frac{v_{2}}{v_{v_{1}}}\right)^{1 / 6}
$$

Note that this is the same relationship as obtained when discussing voids as flaws. 


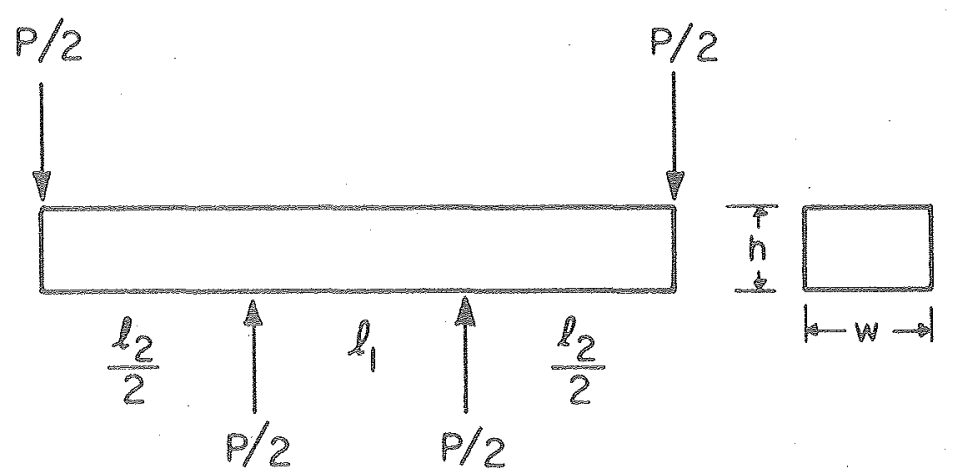

(a)

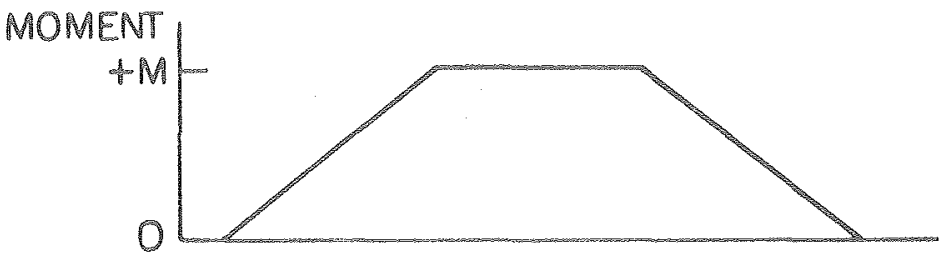

(b)

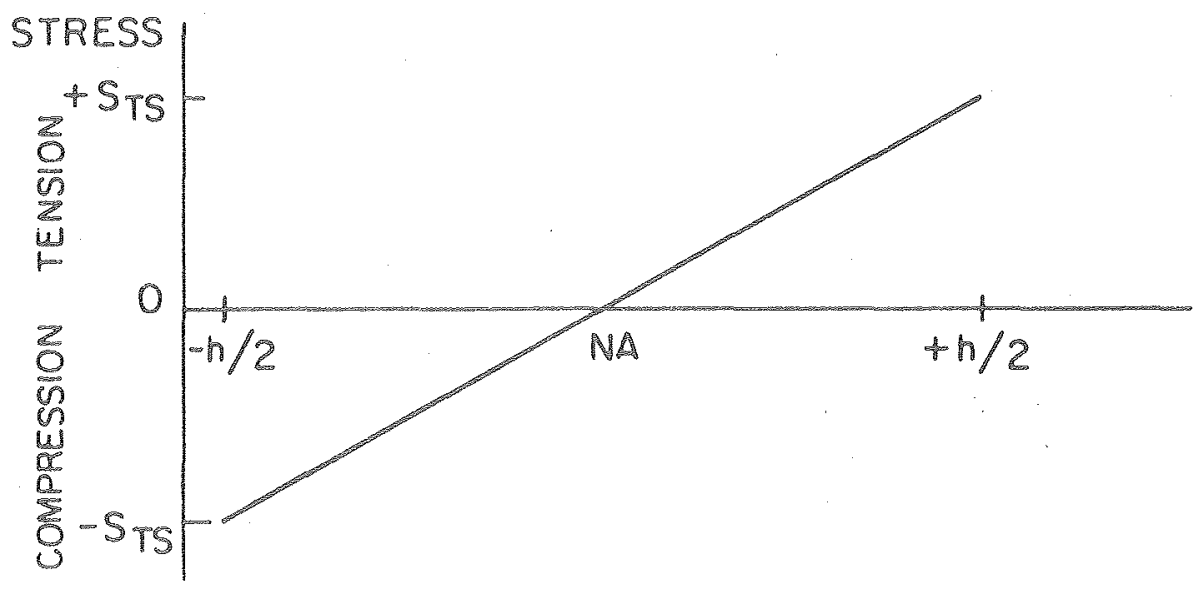

(c)

$\times B L 789-5755$

Fig. 3.1

(a) Loading of test specimen.

(b) Moment distribution, Iongitudinal direction.

(c) Stress distribution, thickness direction. 


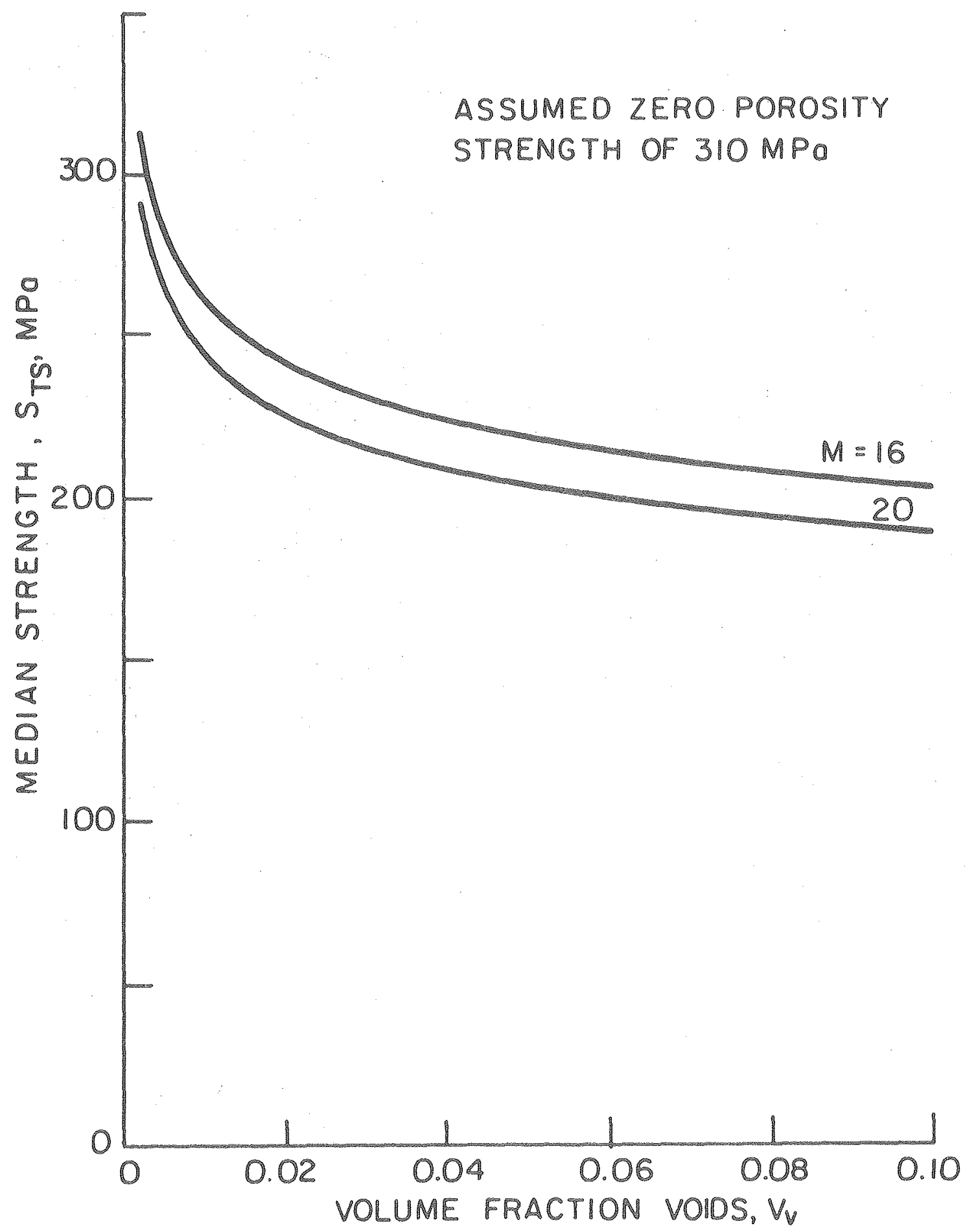

XBL789-5756

Fig. 3.2 


\section{RESULTS AND DISCUSSTON}

\section{Microstructure}

The understanding of virtually all phenomona which involve materials necessarily includes evaluation of the microstructure for possible effects. This microstructural evaluation should take place prior to evaluation of other data in order that expeximental variables axe bettex understood and better utilized.

Preliminary woxk on the selection of the organje used in the generation of voids indicated that a residue of $0.025 \%$ of the organic remained after calcination. It has been well documented ${ }^{25}$ that trace impurities can concentrate at grain boundaries and affect the grain boundary surface energy and thus the sintering behavior and, if the fracture path occurs along grain boundaries (intergranular), the strength. In ordex to determine if the trace impurities from the organic had a significant effect it was necessary to analyze the microstructure for changes with changing impuxity content. Changes In grain boundary energy would necessarily change the dxiving force for sintering and grain growth. This in turn would result in variations in grain size.

Lineal analysis of random microstructures yielded a mean grain size of $8.8 \mu \mathrm{m}$ with no significant size variations with changes in amount of oxganic added. Analysis of the small regions neax voids yielded a grain size similar to that away from voids and in the dense specimens (Fig. $4.1-4.3$ ). 
Fractographic analysis, which will be discussed later, revealed no definite differences in the fraction of intergranular fracture occurring in dense specimens and in specimens with voids, indicating that the grain boundaries in the specimens with voids are not significantly stronger or weaker than those in the dense specimens. Because no changes occurred in grain sizes or fracture surfaces it is concluded that any residue from the organic had no effect on the measured properties of the specimens.

The distribution of extrinsic voids is clearly shown in Figs. 4.44.6. Note that even though thexe are clusters of voids evident in the surface, relatively few yoids are touching. mis would indicate that the clustering is not due to some attractive force such as electrostatic attraction but, rather, is due to random fluctuations in void distribution. A xandon cut through the matrix clearly indicates that the extrinsic voids are spherical in shape and exist in a dense matxix (Fig. 4.3).

Typical tensile surfaces are shown in igs. 4.7-4.9. In particulax, note that the sursaces are in the asmcut condition, as indicated by the scratches $(F i g .47)$, and that the scratches are neariy perpendicular to the Exacture plane. Higher magnification of the tensile surface reveals few pullouts and a limited amount of transgranular Eracture. Examination of the void edges (Fig.4.7) indicates that some chipping occurs duxing cutting. It is interesting to note in Fig. 4.7 that the fracture does not proceed through the cluster of six voids on the tensile surface. This would seem to indicate that 
the stress field from single voids and clusters of voids decays rapidy and that there is little interaction between the propagating crack and othex "Llaws" in the material.

The choice of a "typical" fracture surface is a difficult task because localized regions are often predominantly intergxanular (Fig. 4.10) or transgranular (Eig.4.11). Stereological evaluation of several representative random fracture surfaces indicates that $60 \%$ of the cross-section fractured in an intergranular mode with the remaining $40 \%$ in a transgranular mode. A representative fracture surface $(\sim 65 \%$ intergranular fracture) is shown in Fig. 4.12. No statistically valid differences in the fraction of intergranular Exacture could be detected between those specimens which contain voids and those which did not.

kice 18 noted that in many materials in which the primaxy fracture mode is intergranular there is a change to transgranular fracture axound naturally occurxing pores. In matexial with artificially produced voids there also seems to be a similar change as the crack front propagates past single voids or clusters of voids (Figs.4.11. 4.13 and 4.18$)$. It is believed that this behavior is due to a change in the state of stress at the crack tip because the fxacture mode changes when the crack front passes the voids rather than as it approaches them. It must be noted that the change in fxacture mode does not always occur when the crack Front passes a void (Fig. 4.10). If the regions of transgranular fracture are esamined closely it becomes apparent that thexe are two modes of transgranular eracture: 
1. Fracture which is independent of crystallographic direction as indicated by smooth curved surfaces (Fig. A.11) and 2, Fracture which follows crystallographic dixections (cleavage) as indicated by steps and notched surfaces on a single grain (Fig. 4.15). Very little of the transgranular fracture occurs along crystallographic planes (the second mode). Although the regions which fxacture in the first transgranular mode are relatively featureless, thexmal etching of the grain boundaries (Fig. 4.14) reveals that this transgranulax region actually encompasses many grains; the transgranular fracture is not due to a single large grain and does not revert to intergranular fracture at the first grain boundary but, on the average, propagates through several grains.

It may be appropriate here to reiterate that the primary exacture mode in all samples (with or without voids) is intergranular and that voids are not necessary for transgranulax fracture to occur (Fig. 4.15).

Strength Data and Calculated Values

After reducing the $x$ aw data to the calculated values presented in Table $I$, the first task was to compare these data with proposed empixical and phenomonological strength-porosity relationships. (see refexence 20 for a sumary) Most of these proposed relationships considered only total pore volume and did not considex the effects of pore size and shape. The data from this study (Fig. 4.19) indicate that there is a definite void size effect: therefore, these proposed relationships could be discarded immediately. Unfortunately, the 
remaining relationships which predicted a pore size dependence were not able to accurately predict the data. Only the Weibull approach and extensions of the weibull approach remained as possible "explanations" of the data.

Presented in Table I are the values calculated from the raw data. Both mean and median strength values are reported. The consistency in the experimental values is reflected in the small coefficient of variation values.

A few comments about the calculated strength values are appropriate here. First, all reported values of the strength $\left(S_{\text {TS }}\right)$ will refer to the median strength values, unless otherwise noted, ie, the Characteristic strength ( $\left.S_{0}\right)$. Second, as shown in the curves (Fig. A.19) and the data (Table I), the strength-void fraction relationships are very consistent and reproducible within the void fraction range studied. Also, as shown in Fig. 4.20, there is a definite relationship between the median and Characteristic strengths. It is expected that this relationship, as well as the extrapolation, is accurate since the least squares fit of the data extrapolates through the oxigin。

The Weibull Analysis

The values of the Weibull parameters, $s_{0}$ and $m$, reported in Table $I$ are calculated from a least squares fit of individual sets of data by methods described in section 3. The weighted mean of the individual values is 20.6 . Since vaxiations in values cannot be correlated with variations in void densities, it is believed that 
the scatter in individual m values is due to the small number of specimens being tested. It can easily be seen that one or two high or low strength values out of ter can significantly affect the slope of the $\mathrm{P}_{\mathrm{S}}-\mathrm{S}_{\mathrm{TS}}$ curve but have relatively little effect on the median value. This viewpoint is further strengthened by noting that there is a definite relationship between the coefficient of variation of the strength, $C V$, and $m$ (Fig. A.21). When a weighted mean of the $C V$ values is used in conjunction with the experimentally derived CV $-\mathrm{m}$ curve, a m value of 20.6 is predicted. This prediction compares favorably with that of the weighted mean of the m values (20.6) and, as discussed later, the m value of all normalized data (21.7). For sake of comparison a proposed relationship 21

$$
\mathrm{CV}=\left(\frac{\mathrm{I}}{\mathrm{m}}\right)^{0.94}
$$

is also presented. Even though the expeximental points do not lie on the proposed curve, the consistency of the data and the paralle1 nature of the two curves is obvious.

Finnie 21 indicated that data from different sizes of specimens and different types of tests can be pooled if each strength observation is normalized by the median strength for that set of specimens. When the strength values of the specimens of a set (void fraction-void size) were normalized by the median strength of that set and the normalized values for all 198 bend specimens were ranked and plotted. the composite curve in Fig. 4.22 resulted. A least squares fit of these data yielded an $\mathrm{m}$ value (slope) of 21.7 , a value nearly equal to that of the weighted mean of the malues $(20.6)$. Close examination 
of the curve indicates separate regions of different slopes. The change in slope, if significant, could indicate the existance of two separate flaw populations. Since previous work ${ }^{17}$ indicated that surface flaws were not one of the populations, both populations would necessarily exist within the bulk of the material.

We must digress here to further consider the meaning of characteristic strength and the relationship to the material under considexation. As discussed in section 3, the prediction of strength for specimens of volume differing from that of the test volume assumes that the Characteristic strengths and Wejbull Moduli are identical for each sample of material. This assumption states that the failure mechanisms and flaw populations are the same for each sample: for a given loading condition (state of stress) che Weibull parametexs must be constants characterizing the particular batch of materials. Conversely, for similar loading conditions (state of stress) and failure mechanisms (flaw populations) the Weibull paxametexs must be identical for each set of specinens independent of stressed volume. It must be noted, as discussed by Pankow, ${ }^{19}$ that weibull parameters are not constant when the stxessed volume becomes extremely small. The reason for this is presumably due to changes in the failure mechanism or inhomogeneity on a microscale. This of course places limits on the minimum size of the stressed volumes if valid comparisons of weibull parameters are to be made.

In ordex to compare the stressed volumes of samples which contain introduced discontinuities it is not sufficient to compare bulk volumes. 
Instead, we must calculate the volume of naterial which sees the stress field of the discontinuity superimposed over the nominal stress field; for convenience we shall call this volume the stressed volume. It can be shown that the stressed volume of samples which contain voids is dependent only on the void fraction (independent of void size). Assuming that the specimen fails from a flaw within the stressed volume (rather than from a flaw within the nominal stress field) then a plot of $s_{0}-V_{y}$ should yield a single curve for all vold sizes. It can be seen in Fig. 4.23 that all data does not fall on a single curve (correlation coefficient for a straight line is 0.87 ). Closex examination of the data points indicates that there are three independent curves, each representing a different void size (Fig. 4.24). Least squares fit of the data points indicates an excellent straight line fit for the $48 \mu \mathrm{m}$ and $80 \mu \mathrm{m}$ voids (correlation coefficient $\geqslant 0.96$ ): it becomes obvious that the data points are members of distinct families. The data for the $28 \mu \mathrm{m}$ voids is not so convincing. The reason for the greatex scatter for the $\mathrm{s}_{0}$ values of the $28 \mathrm{\mu m}$ void size is not obvious at this time.

The fact that distinct curves exist for different void diameter indicates that fundamental exrors exist in this formulation. One of the more satisfying explanations is that the stress field of a void does not extend over several grain boundaries for the smallex void sizes. This is not a problem in statistical sampling of single grain boundaries but, rather, a problem of sampling multiple continuous grain boundaries. This might also explain the scatter in the so values 
For the 28 m void size. Another possible explanation is that the specimens do not Eail from Elaws within the stressed volume but from flaws within the rominal stress field. This change should result in very low $m$ values for small void fractions because a few specimens would fail from flaws in the stress field of the void thus be very weak. However, the correlation between small $v_{v}$ and small m does not seen to exist (Table I). Existence of varying values for $s_{0}$ with changes in void Eraction for the largest void size (80 $\mathrm{\mu m}$ ) seems to indicate that statistical sampling exrors may not be the cause of the variations but, rather, fundanental exrors in this analysis and, perhaps, in the weibull formulation may be the cause.

Introduced Stress Fields

Section 3 presented the Weibull approach and several modifications to the weibull approach which might prove useful in analysis of the system under study. The work of vardar et al proposed to provide the most direct test of Weibull statistics as no modifications were made to Weibull's analysis. Instead, modifications were made to the equations describing the stress field which existed within the sample; thus the Risk of Rupture.

The data presented in Vardar's paper supports his evaluation very well. However, the data generated in this study does not support the analysis nearly so well. Pexhaps the most critical difference is the strength dependence on vold size noted in this study. The Vardar modification of Weibuld's analysis predicts that the strength of bodies which contain sphexical voids is dependent on the void fraction 
and independent of void size. The data from this study indicates that the strength is a function of void size as well as void fraction and that the plots of $S_{\text {med }}-V_{\mathrm{v}}$ are nearly linear over the void fraction ranges studied as opposed to his prediction. In addition, the median strengths at high void fractions are lower than predicted (Fig. 4.25).

The question becomes: What are the primary differences in the two studies? The fundamental difference seems to be in the choice of materials: lead-zirconate-titinate (PZT) versus alunina. A previous study $^{22}$ indicated that there is probably a continuous second phase present at grain boundaries in PZT due to the evaporative liquid-phase sintering technique used in matexial fabxication. Because PZT fails by a primarily intergranular mode, a grain boundary phase could have a significant influence on the strength. The alumina used in this study has no detectable second phase. A second difference is the grain size/void size ratio. It has been suggested ${ }^{23}$ that the relatively small grain size/void size' ratio in this study could account for the descrepancies. Indeed, it may be noted that the grain size/void size ratio for the largest void size $(80 \mathrm{~mm})$ is within the range studied by Vardar and provides the closest fit to his prediction for $0.02<v_{y}<0.06$. However, a significant deviation exists for $v_{y}>0.07$. pankow 19 has indicated that for fractuxe statistics to be valid there should be greater than 100 - stressed grain boundaries, perhaps several hundred. Examination of Fig. 4.5 seems to indicate that this critexion has been fulfilled, at least for the specimens with highex void fractions. If the statistical criterion has not been fulfilled 
then one would expect a rash of specimens which are stronger than predicted and thus a decrease in the slope of the Weibull plot. In Eact, the Weibull plot of the normalized values (Fig. 4.22) does show a decrease in slope (if significant) but there appear to be far too many specimens in this region to correspond to only the small void Eraction specimens.

Extension of the Weibu11 Analysis Based on Microstructural Parameters Comparison of the data and the three hypothesis based on observable microstructural features, ie, void-grain boundary interaction, voids as flaw and flaw-flaw interactions axe lumped into this sub section for one reason: they do not correlate well with the data. Does this mean that there is no correlation between chese microstructural features and strength. Based on the volume of evidence that observable microstructural featuxes and strength? Based on the volume of evidence that observable microstructural parameters have an effect on strength. ie, strength-grain size relationships, and relationships between changes in Eracture mode and grain size, the answer to this question must be "NO".

Before proceeding further we should compare the experimental results to the predictions of these hypotheses. The void-grain boundary interaction hypothesis predicts that a plot of $2 n s_{\text {med }}$ vs. in $\left(\frac{\mathrm{d}}{v_{x}}\right)$ will produce a single straight line fox all void sizes with a slope of $\frac{1}{m}$. plotting the data in this manner (Fig. 4.26) results in three separate curved lines. The volds as flaws and flaw-flaw interaction hypotheses both predict that a plot of $\mathrm{S}_{\mathrm{ms}} / \mathrm{S}_{\mathrm{TS}} \mathrm{VS}_{2}\left(\mathrm{~V}_{\mathrm{V}_{2}} / \mathrm{V}_{\mathrm{V}_{1}}\right)^{1 / 6}$ 
will produce a straight line for a 11 data points. Figure 4.27 indicates that three separate curves result (the curves are sketched in for claxification). Note that the relative values of $\mathrm{S}_{\mathrm{TS}}$ and $\mathrm{V}_{\mathrm{y}}$ are referenced to $S_{\mathrm{TS}_{2}}=235$ and $\mathrm{V}_{\mathrm{v}_{2}}=.038$ for the 48 um void size. Even though this selection was arbitrary, other selections yielded similar results. 


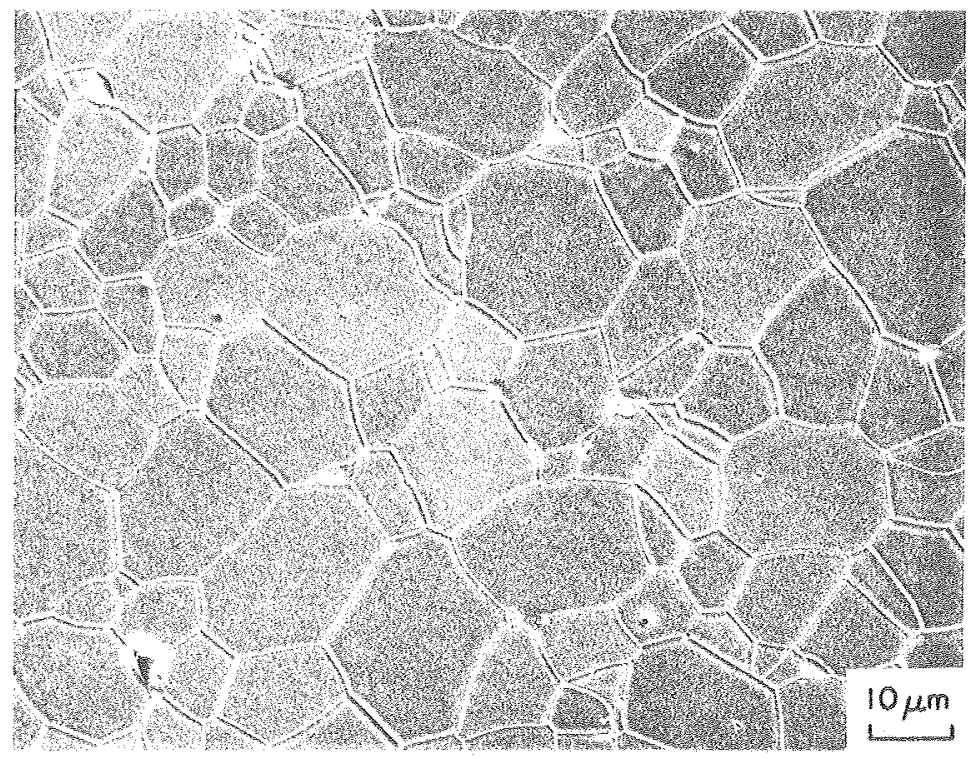

Fig. A.1. Polished and thermally etched section of a dense specimen. $\bar{l}=9.0$

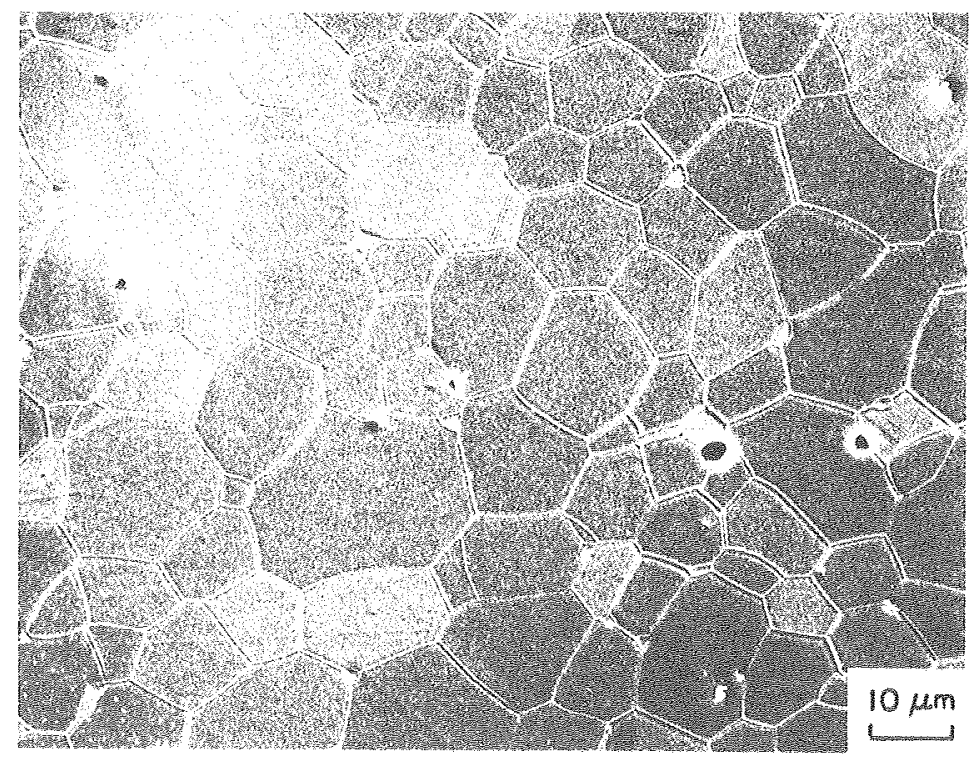

Fig. 4.2. Polished and eteched section of a specimen which concains 0.12 vold Eraction (voids not visable)

$\ddot{l}=8.8 \mu m$ 


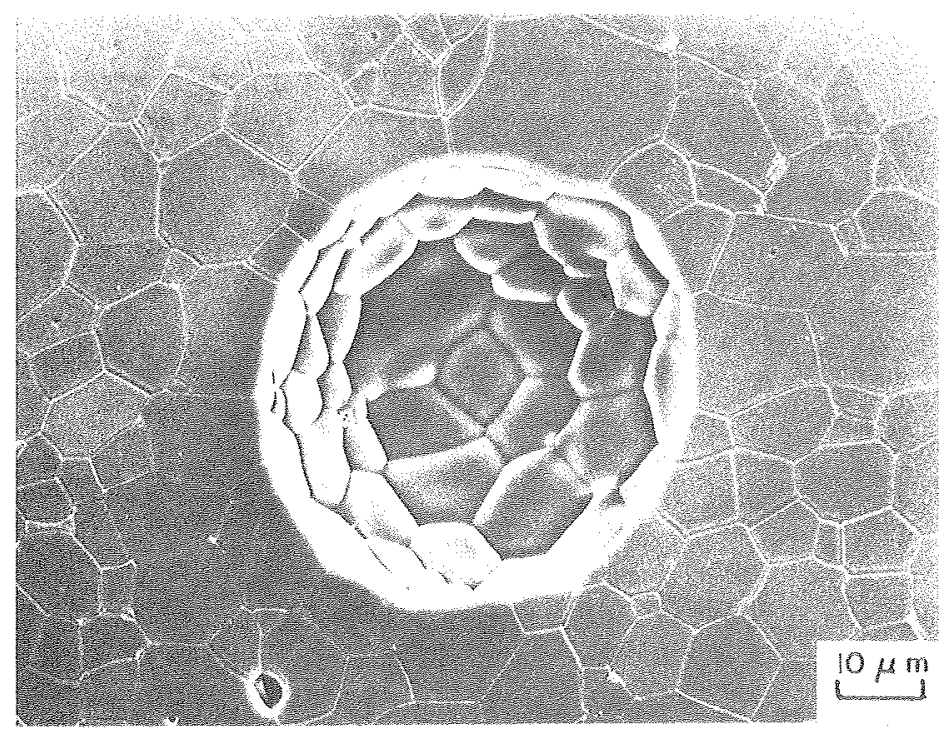

Fig. 4.3. polished and etched section. Note the symmetry of the void and the laxce numbex of grain boundaries which intersect it.

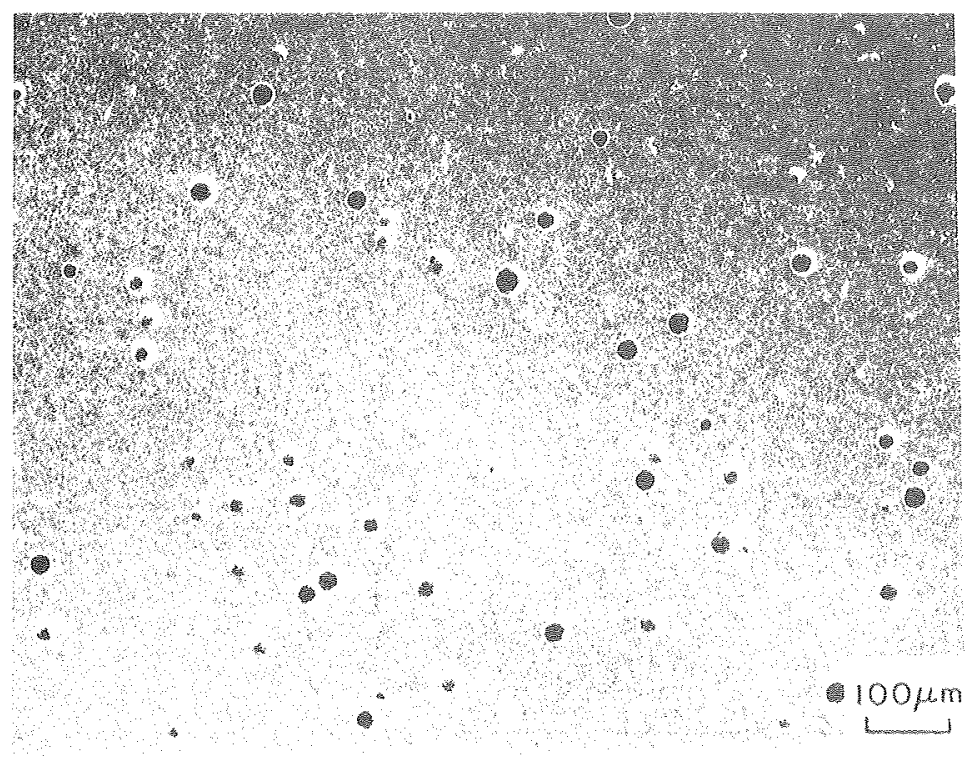

Fig. A.4. Polished and etched section. $\left(v_{v} \sim 0.02, a=28 \mu m\right)$ 


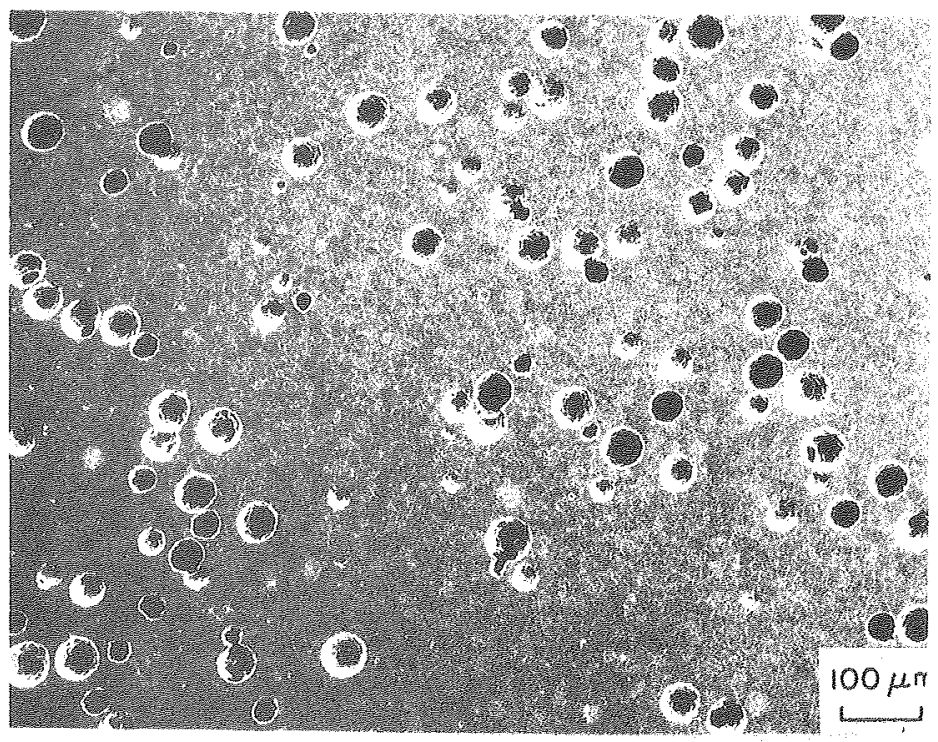

HM. 4.5. Polished and etched section.

$\left(V_{\mathrm{y}} \sim 0.06, d=48 \mu \mathrm{m}\right)$ void clustering apparent.

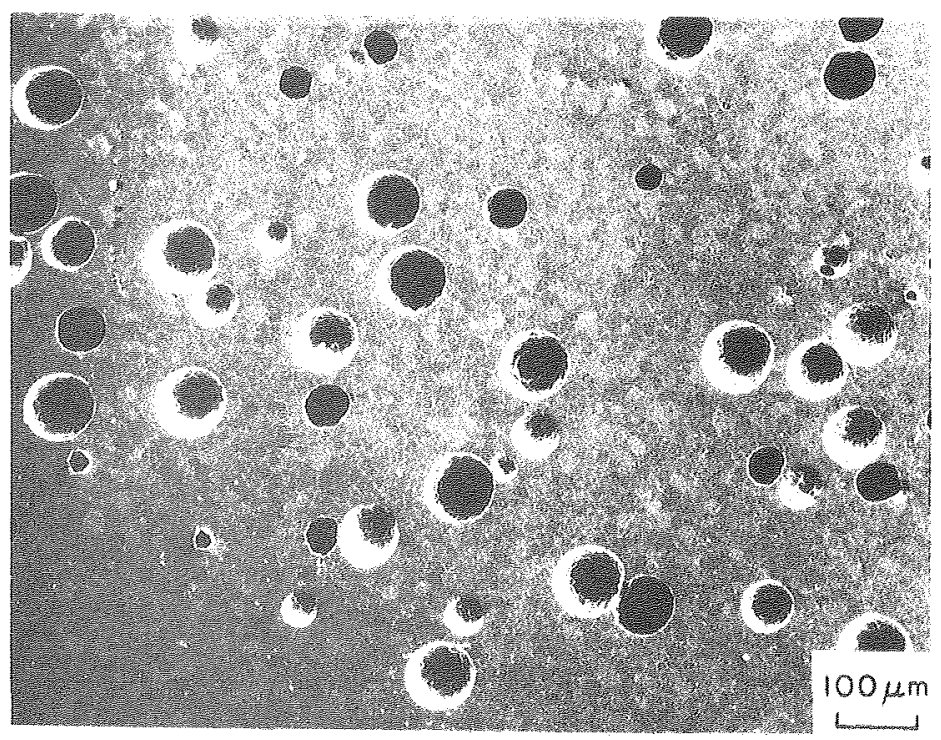

Fig. 4.6. Polished and etched section.

$(v \sim 0.04, a=80)$ many voids approach each othex but few actually touch. 


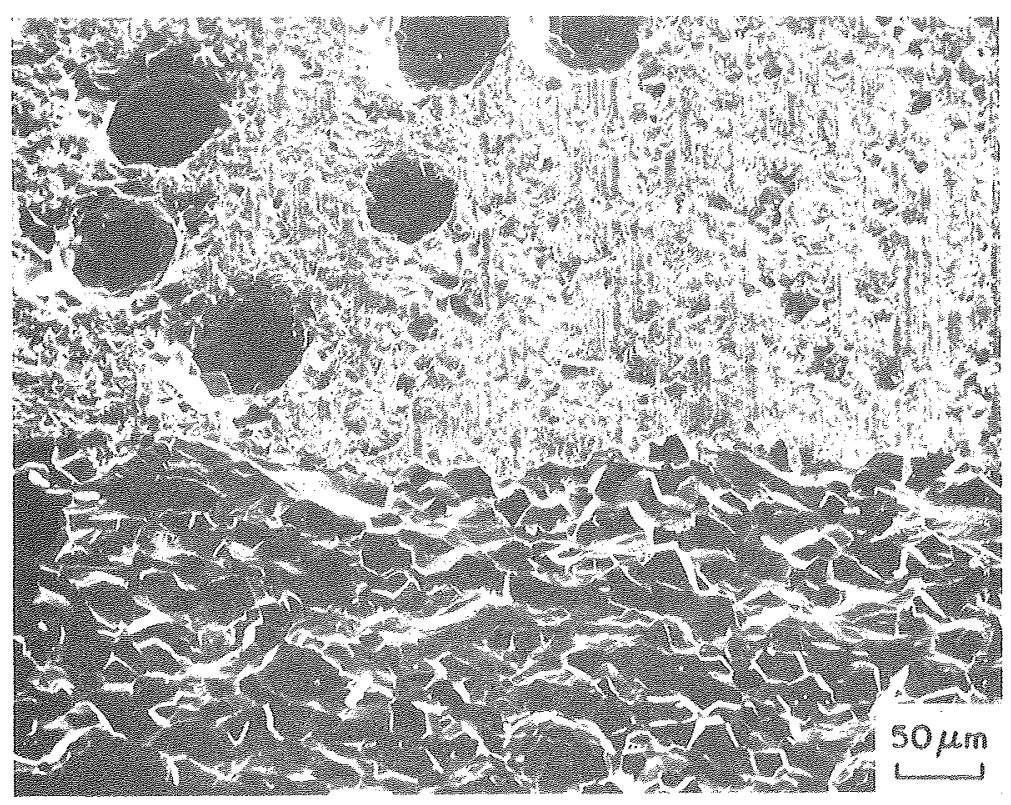

Fig. 4.7. Asmcut tensile surface/fracture surface. The parallel lines are machining marks on the tensile surface.

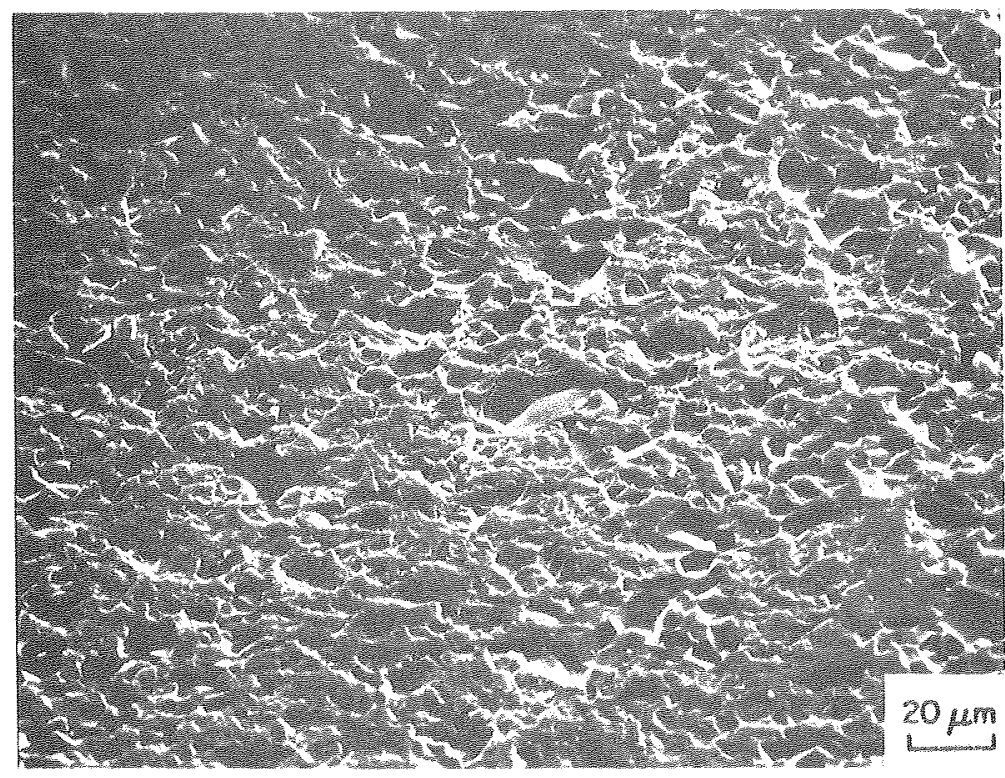

Fig. 4.8. As-cut tensile surface. X8B $789-10747$ 


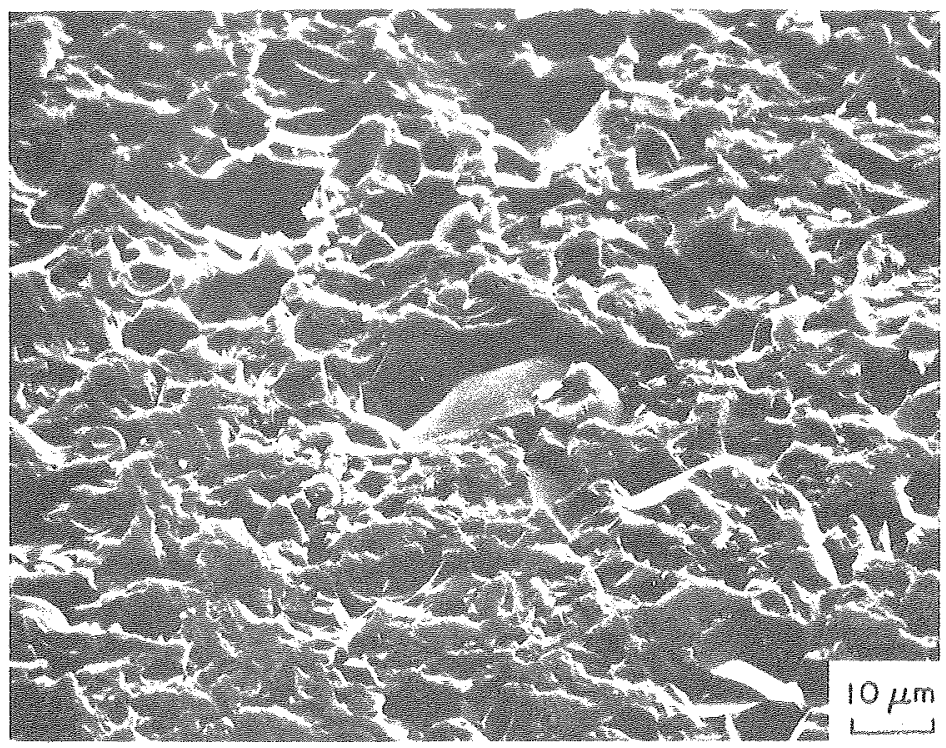

Fig. 4.9. Detail of as-cut tensile surface.

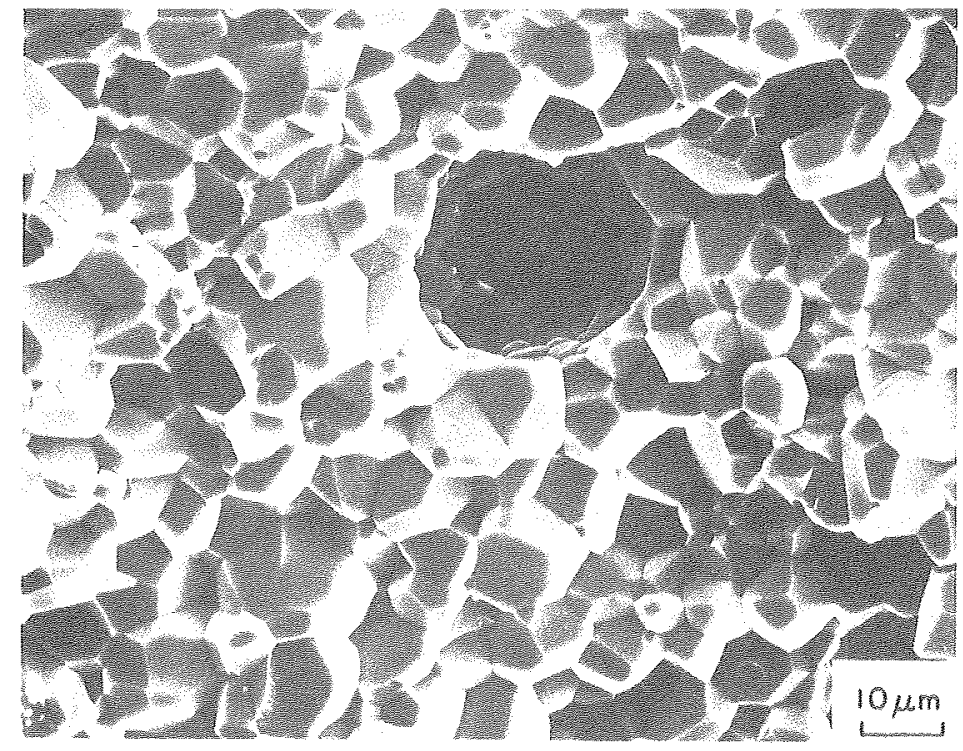

XBB $789-10746$

Fig. 4.10. Fracture surface. Intergranular

fracture near artificially produced void. 


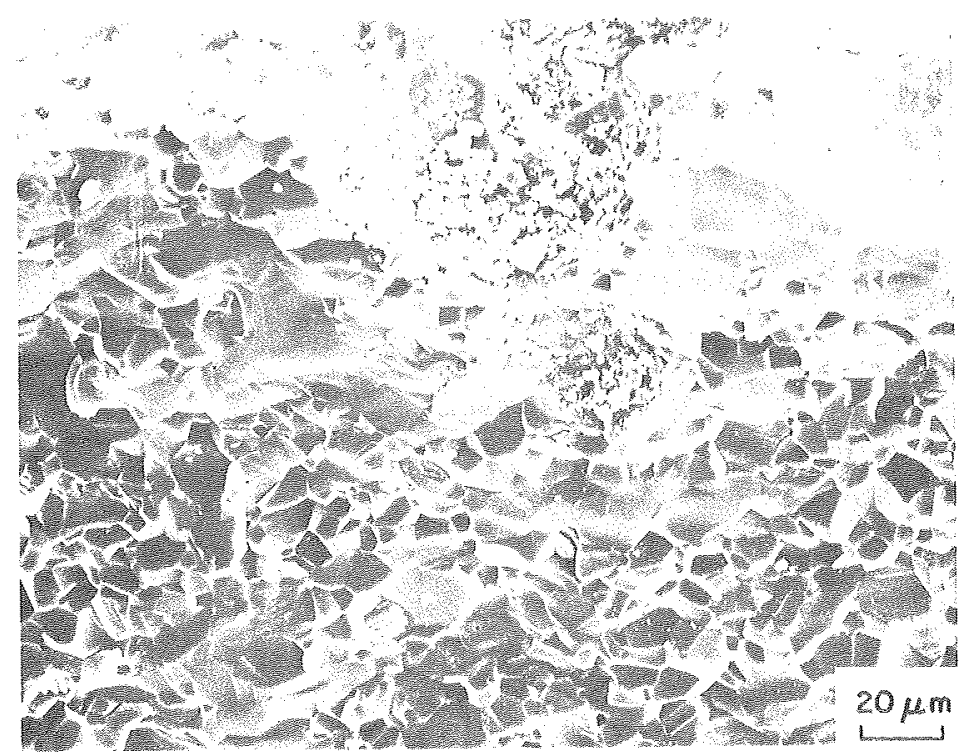

Fig. 4.11. Tensile surface/Eracture surface. Pxedominantly transgranulax fracture below tensile surface neax yoids.

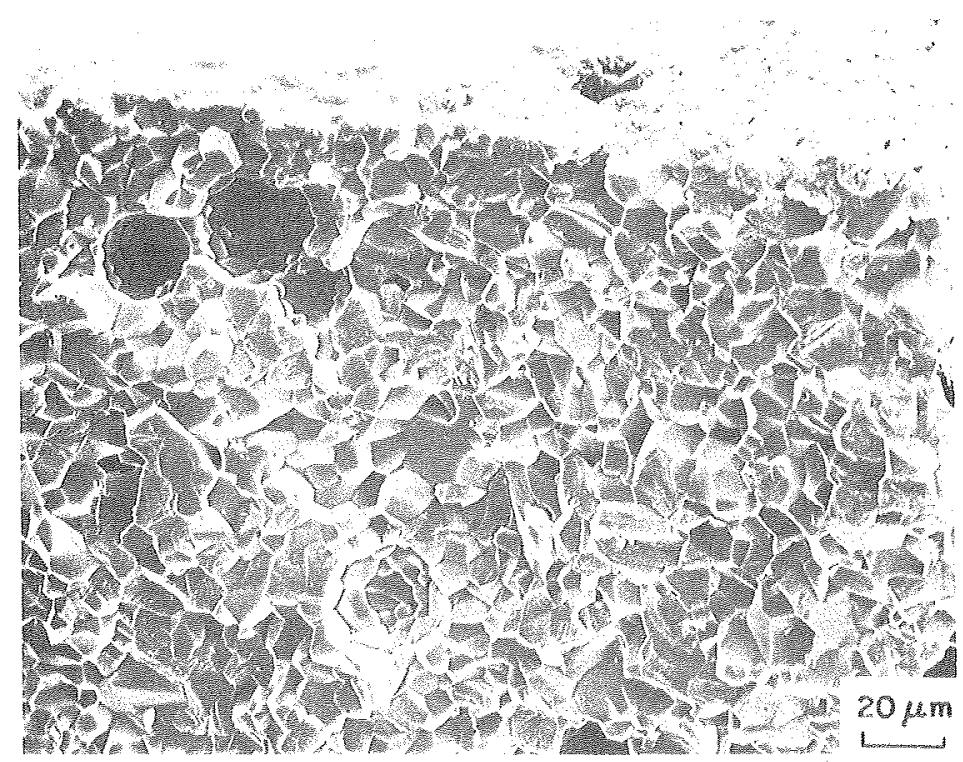

Fig. 4.22. Fracture surface/tensile surface. Predominanty intergranular fracture below tensile surface near voids.

XBB 789-10745 


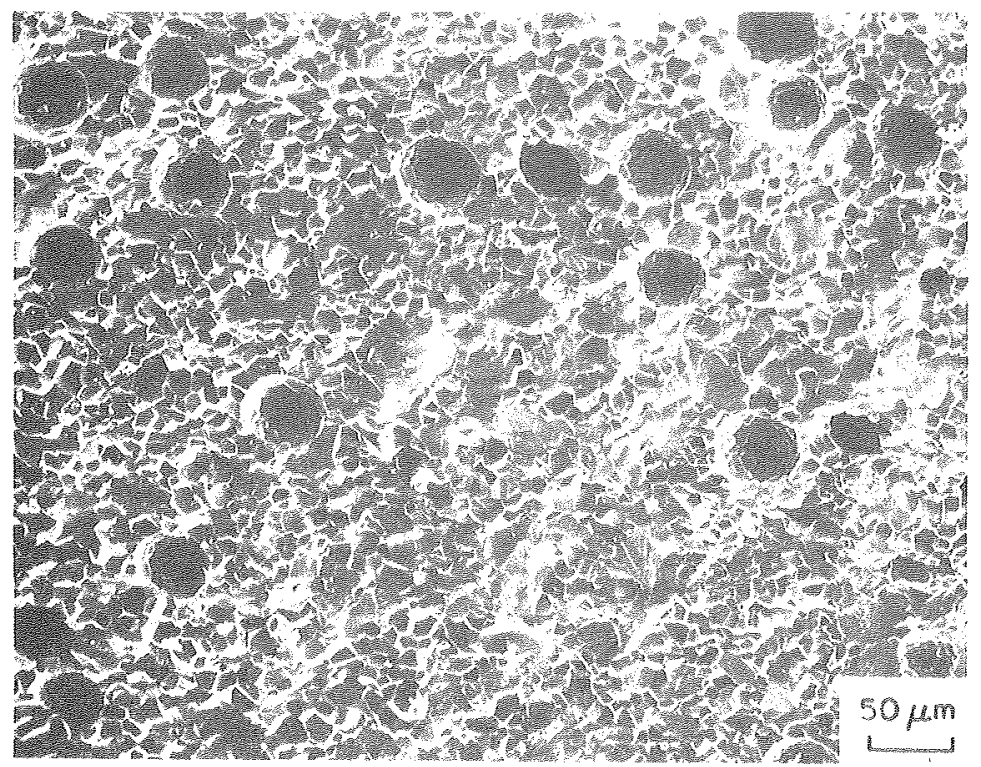

Fig. 4.13. Fracture surface. The direction of crack propagation is from top to bottom. Note the change in Fracture mode when the crack passed the voids.

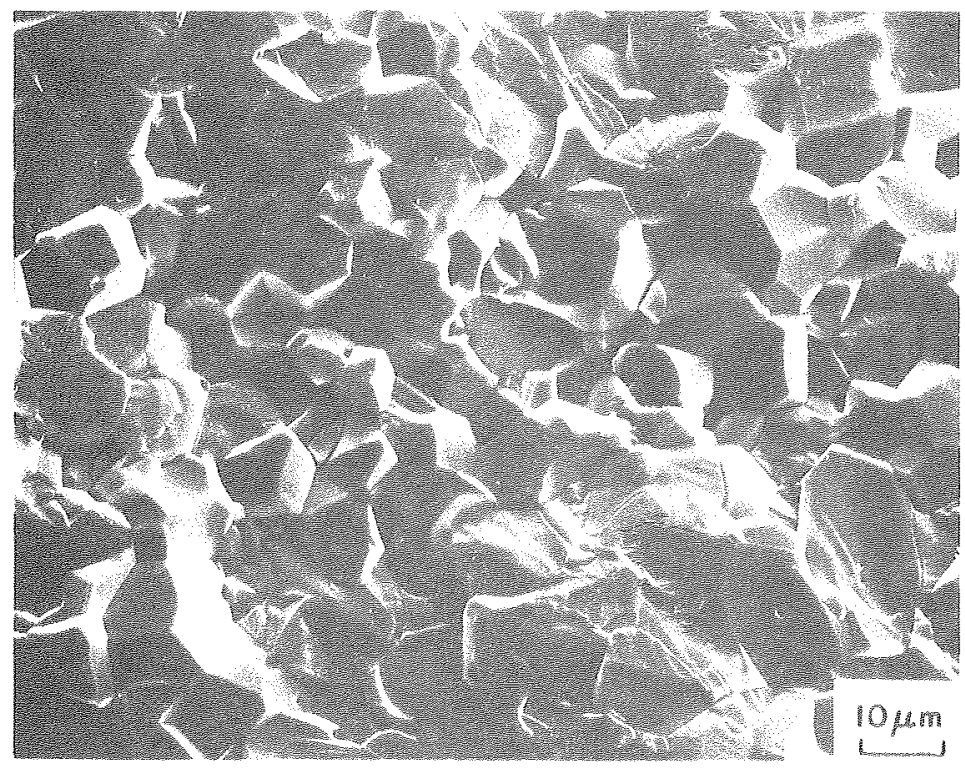

Fig. 4.14. Thermally etched fracture surface. The thermal etch delineates the grain boundaries in the otherwise featureless transgranular fractuxe region. 


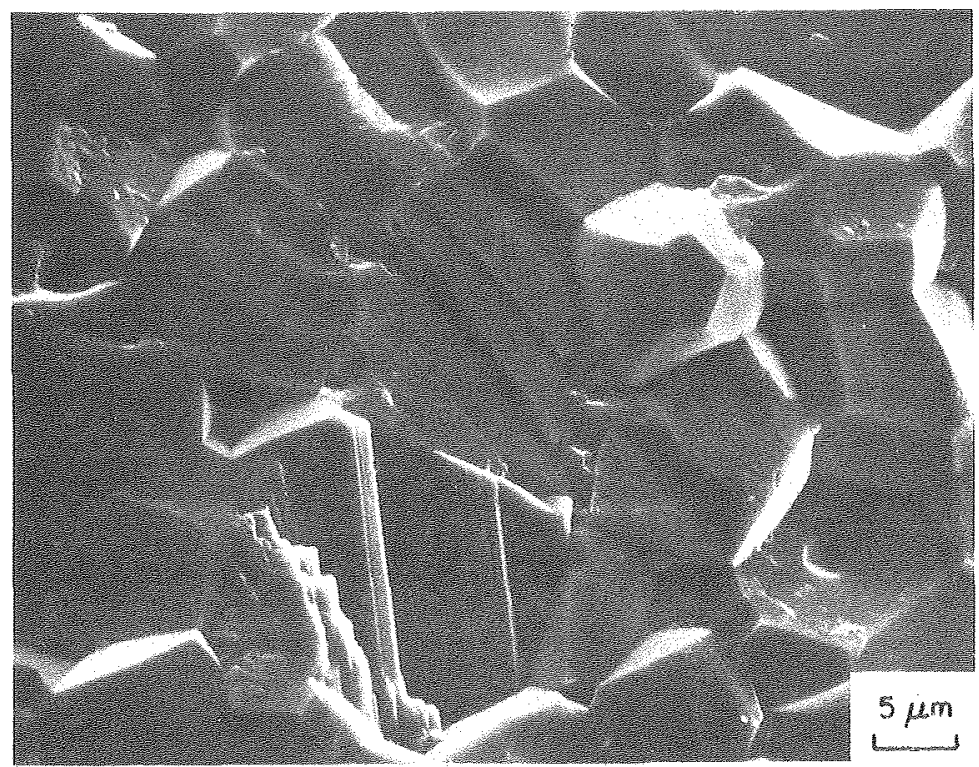

Fig. 4.15. Fracture surface. The steps are indicative of transgranular fracture which has followed crystallographic dixections.

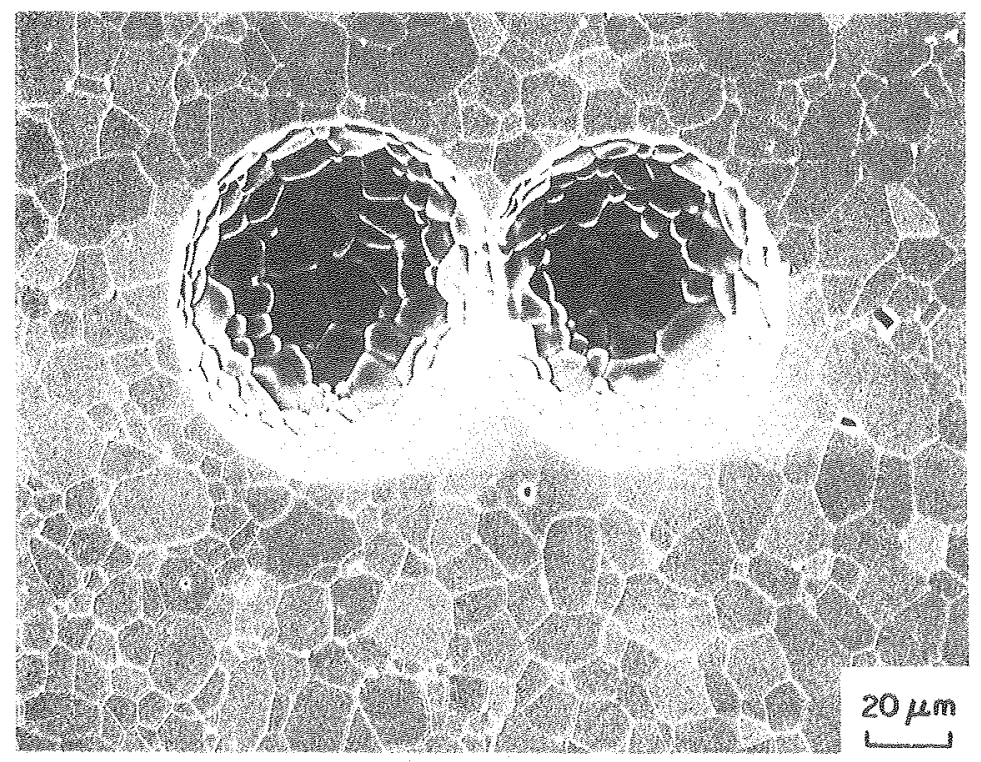

Fig. 4.16. polished and etched surface, linking of two voids. 


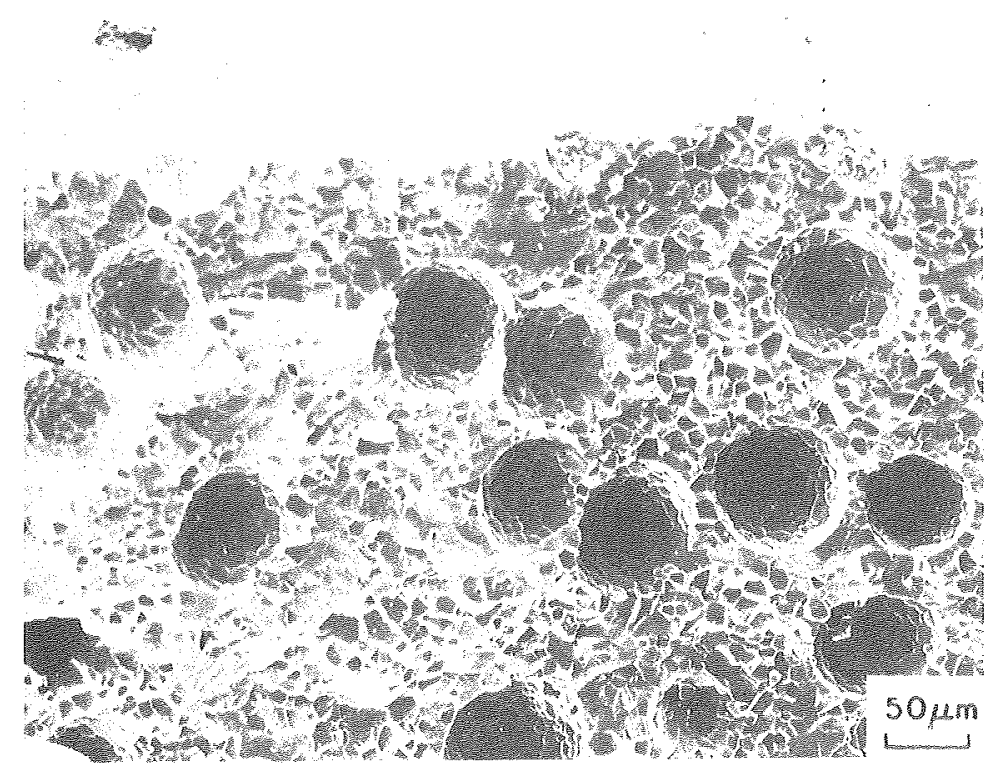

Fig. 4.17. Tensile surface/fracture surface. Iaxge cluster of voids beneath the tensile surface.

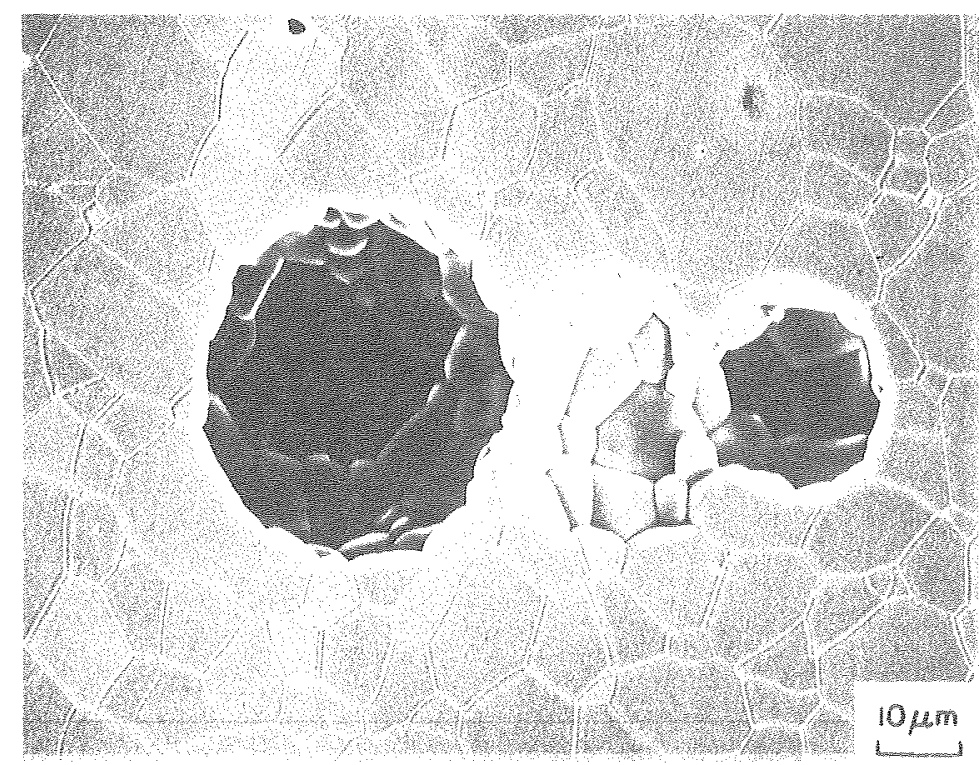

XBB $789-10743$

Fig. 4.18. Polished and etched surface. Iinking of three voids. 


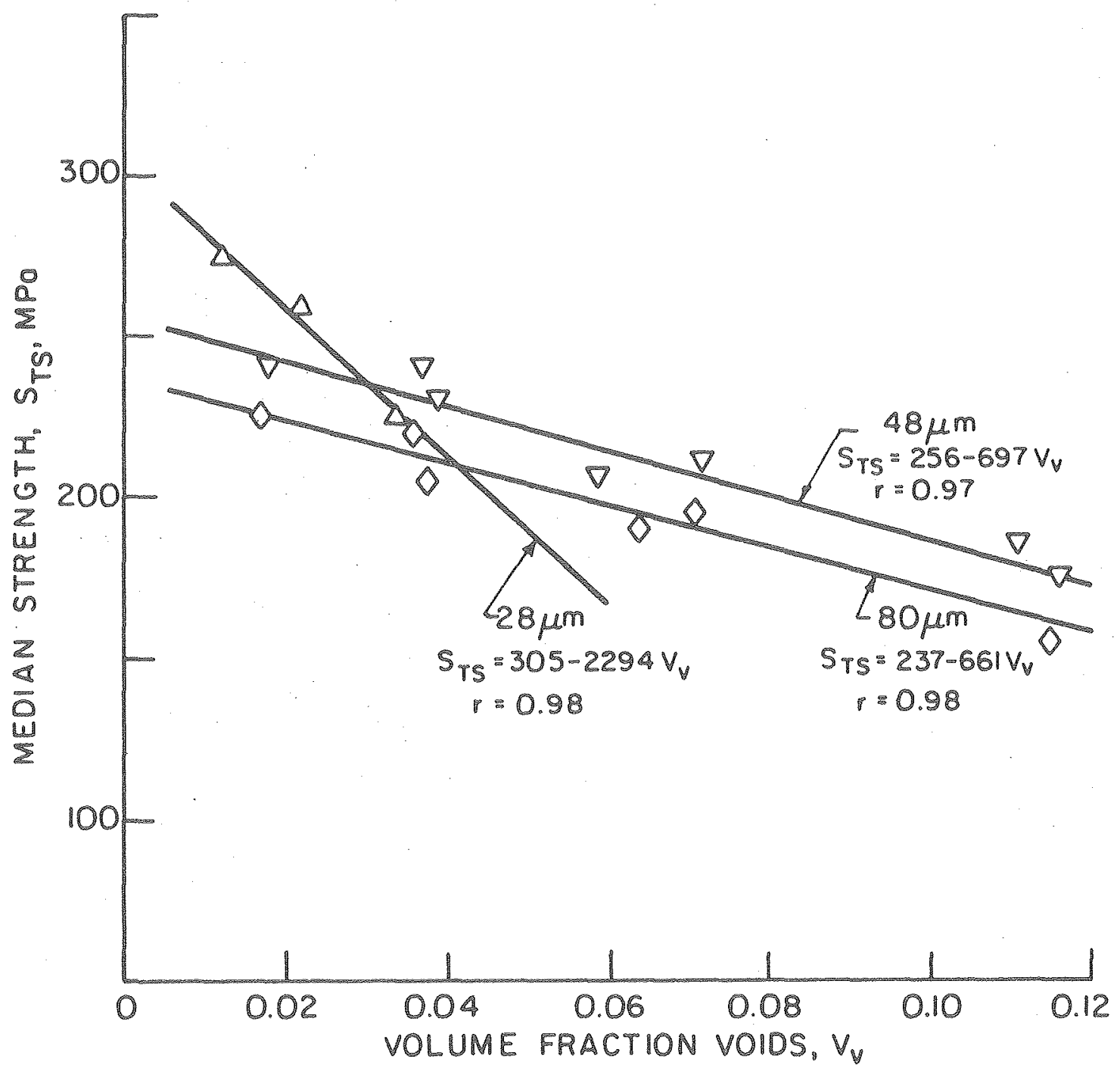

XBL789.5757

F1. 4.19 


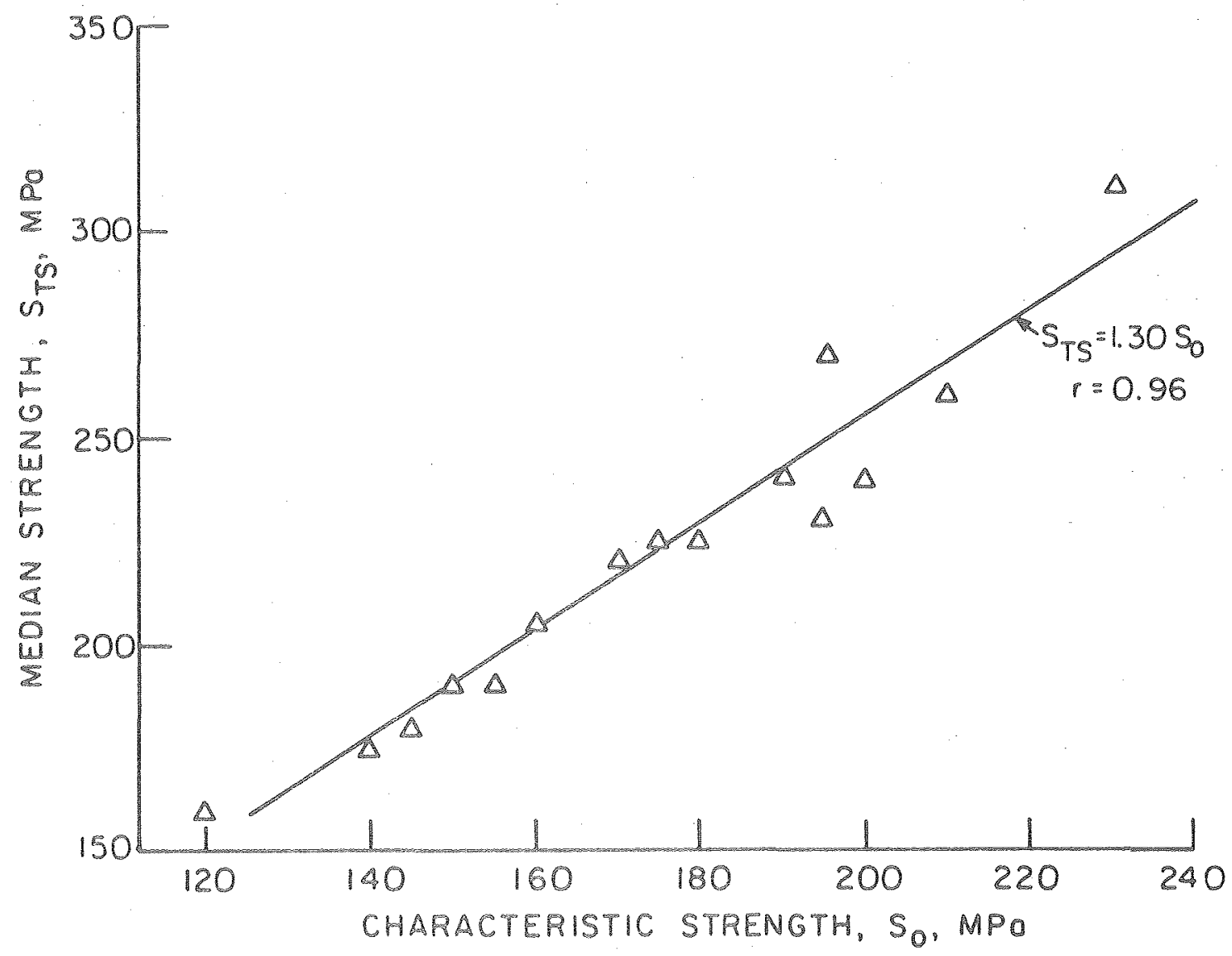

$\times 84789.5758$

Fig. 4.20 


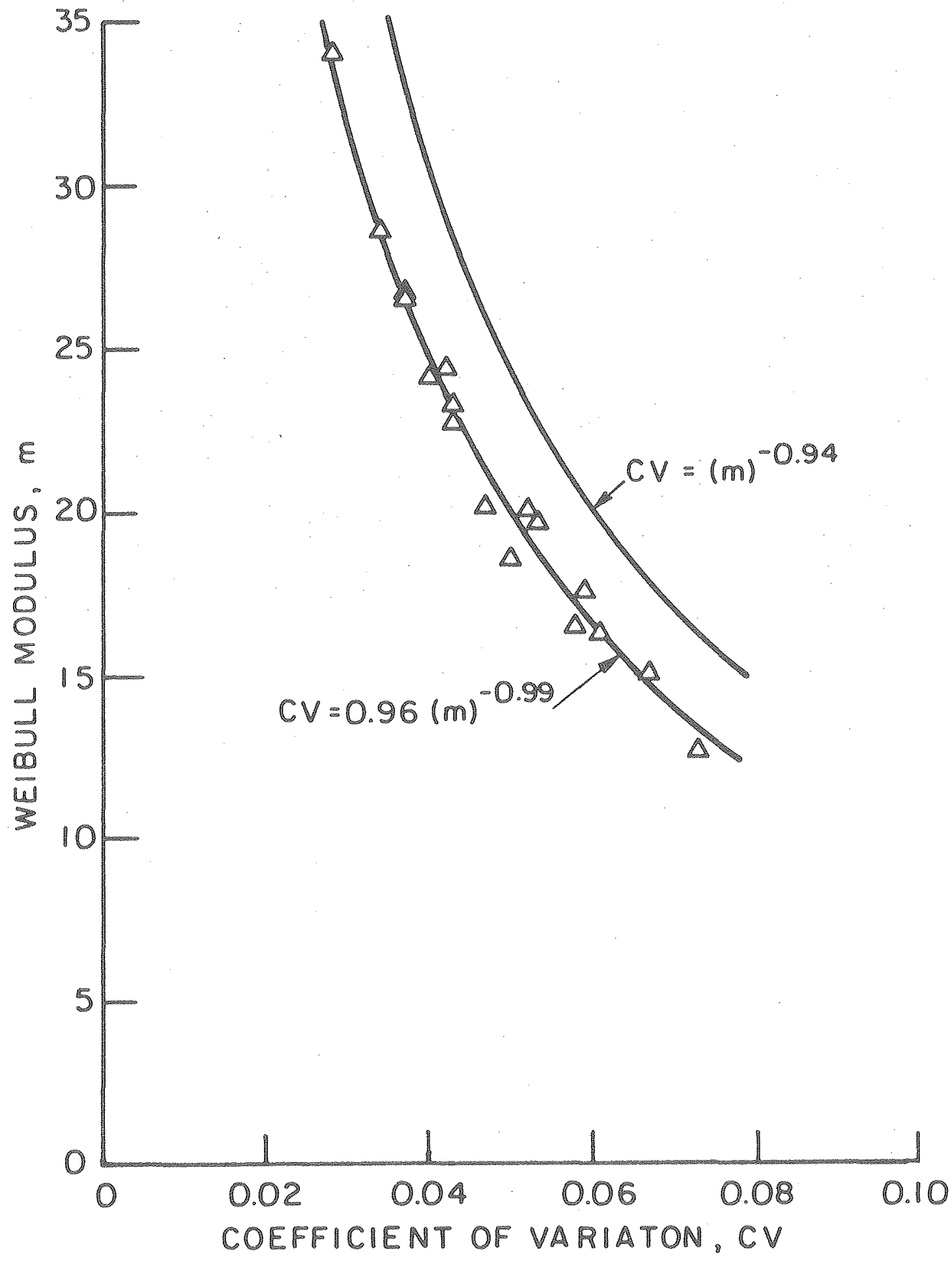

XBL789.5759

Fig. 4.21 


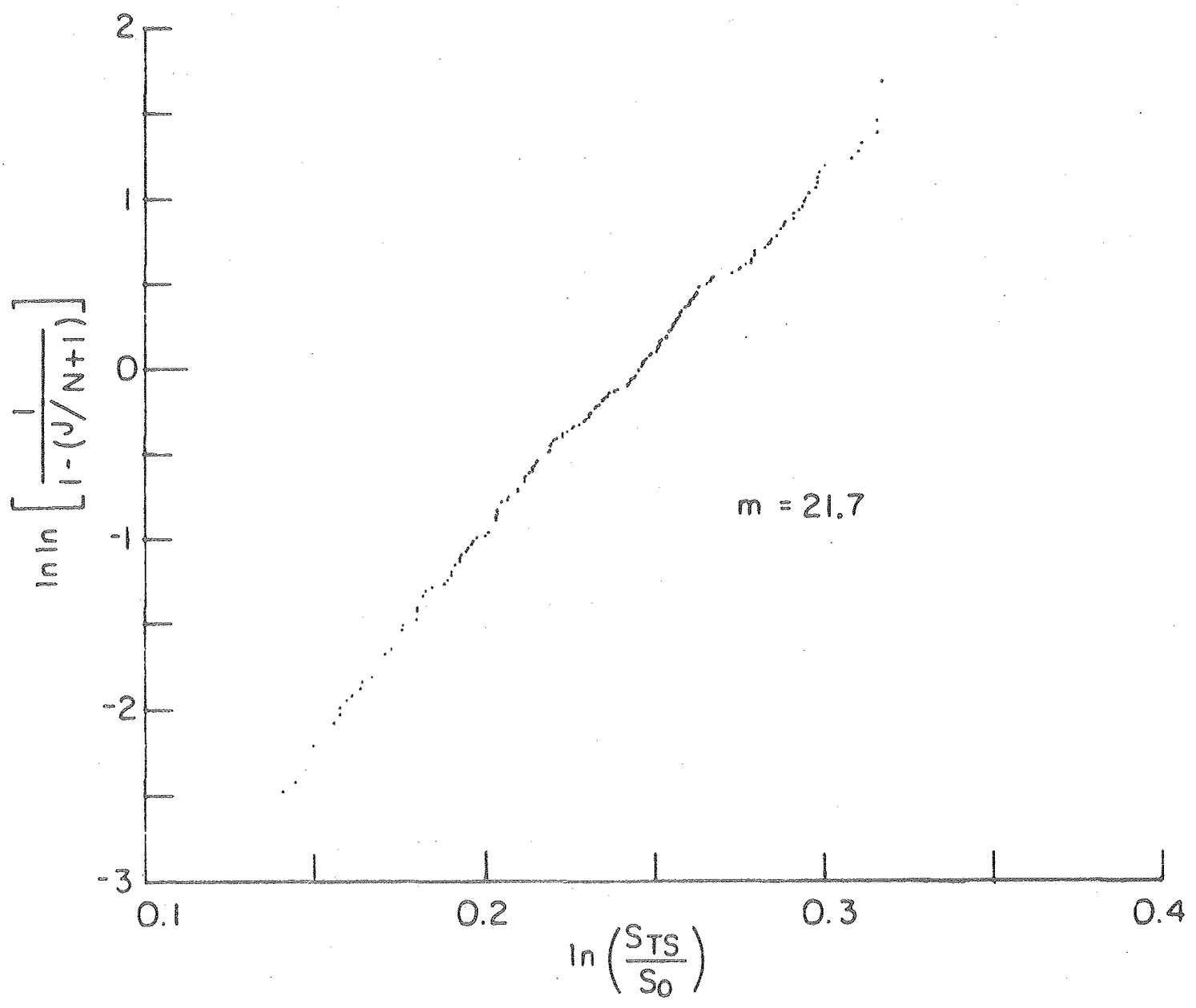

XBL789-5760

F1g. 4.22 


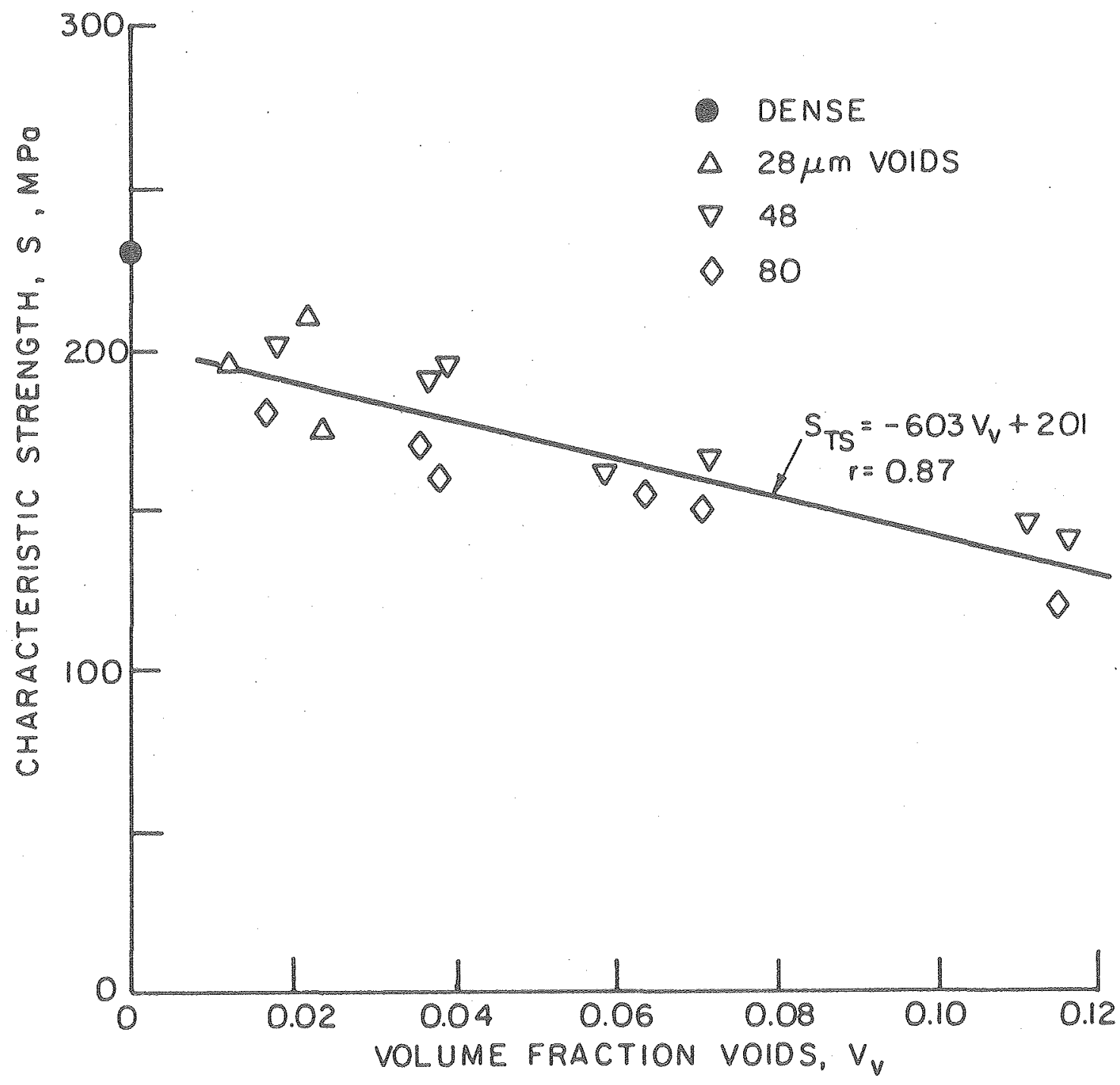

X8L789.5761

Flg. 4.23 


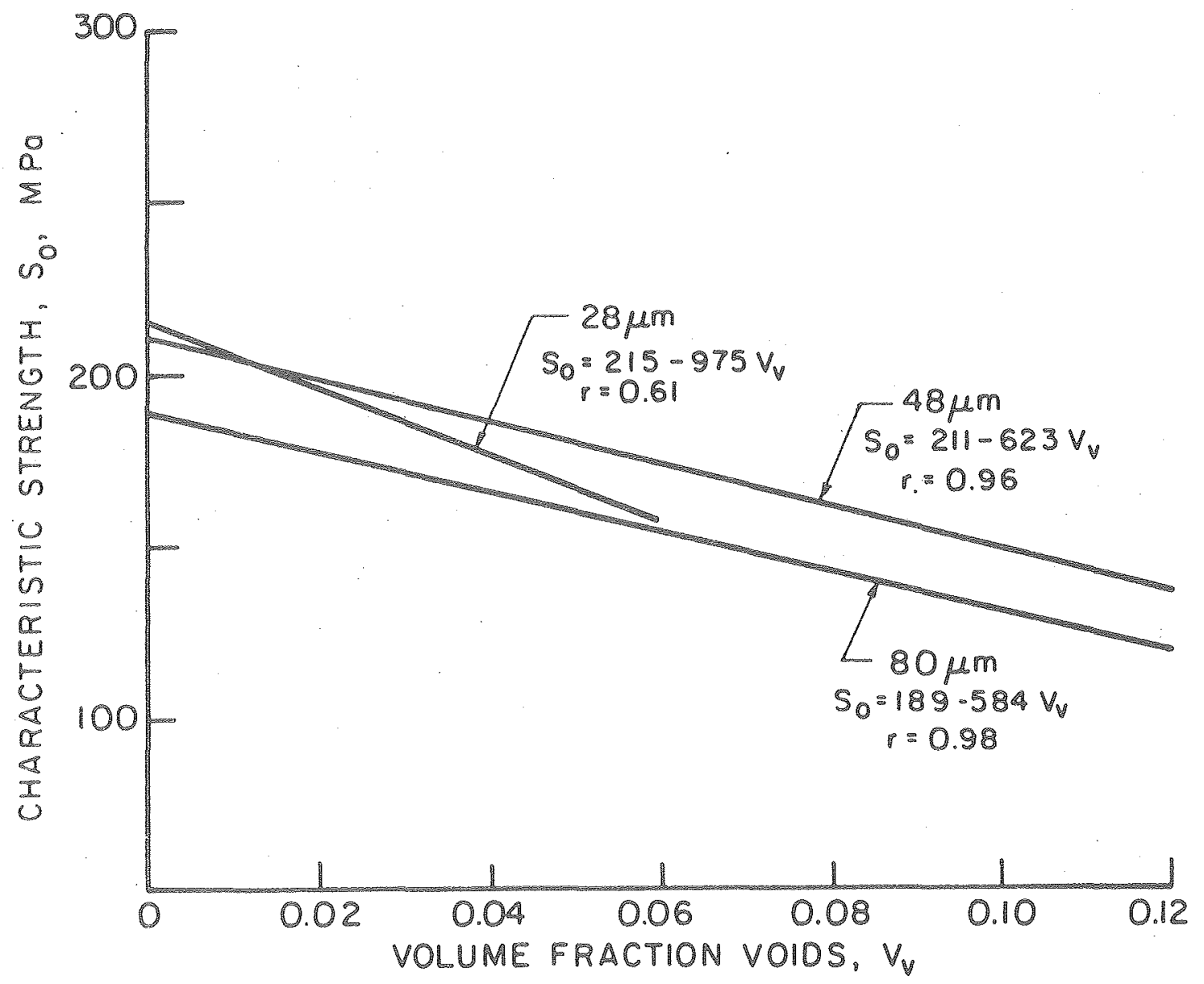

xa 789.5762

FIg. 4.24 


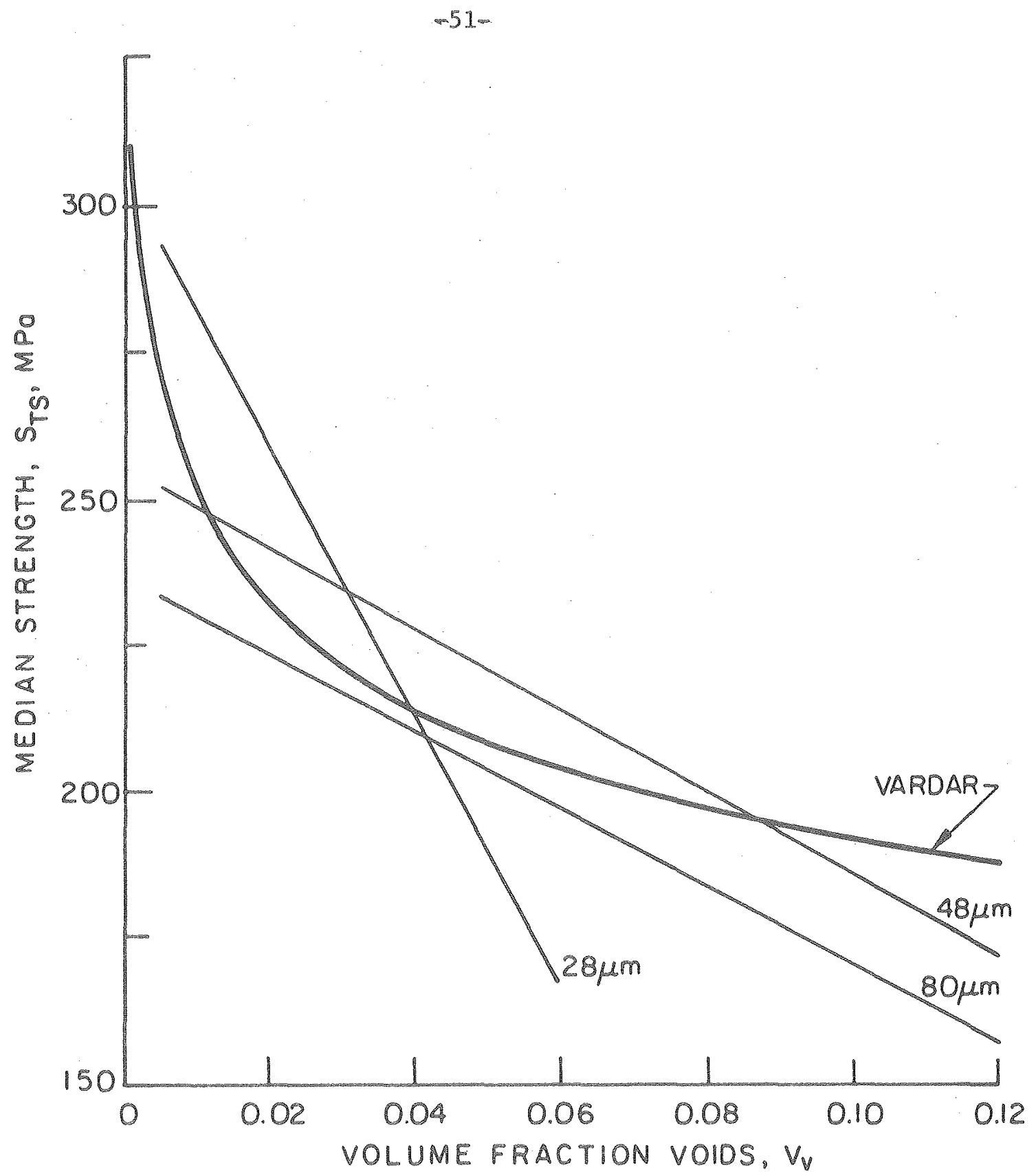

X8L 789.5763

FIg. 4.25 


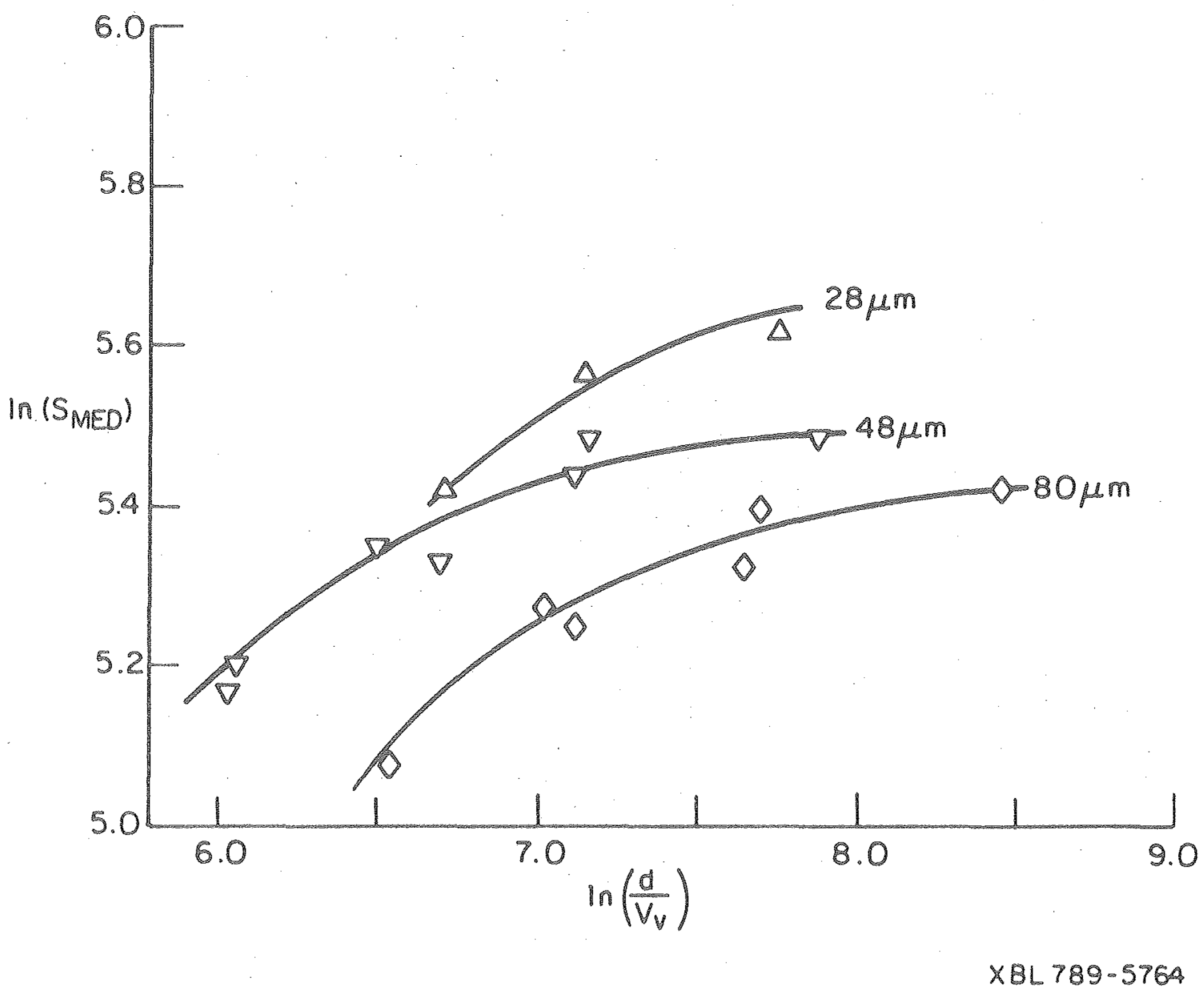

Fig. 4.26 


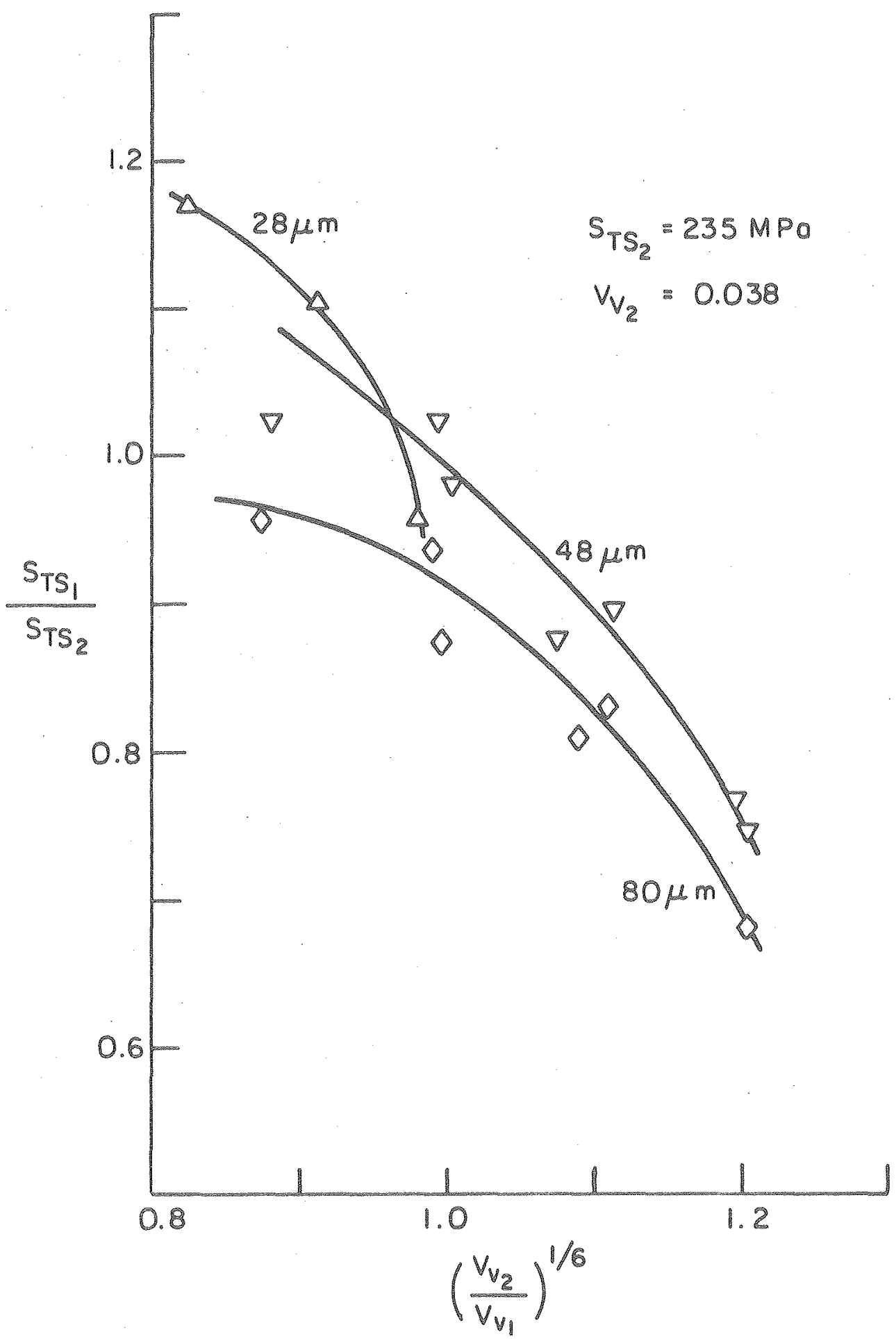

X1L789-5765

FIg. 4.27 


\section{DISCUSSION}

We have seen fxom the pxeceeding sections that the data of this study, while consistent unto itself, does not correlate well with any of the proposed empirical or phenomenological relationships, extensions of Weibull analysis or microstructural relationships. However. the normalized data when pooled togethex do fit the weibull plots very wel1. These favoxable pooling results seem to indicate that a1 specimens failed from the same flaw populations. The fact that Vardar's modified stress field used in conjunction with the Weibull analysis did not prove fruitful would seem to xefute this contention.

One of the basic assumptions on which the weibull approach is founded is that thexe is no Elaw-flaw intexaction. This was assumed because, as noted in section 3.5, correcting for any flaweflaw interactions is nearly impossible. However, photomicrographs of random polished surfaces and sracture surfaces clearly show evidence of void pairs (Figs. 4.6 and 4.16 ), void triplets (Figs. 4.12 and 4.17 ) and void clusters (Figs. 4.5 and 4.18 ). Since the theory of Eailure of brittle solids is based on the well founded assumption that the most severe Flaw (weakest link) is responsible for the failure strength of the specimen, how can the Weibull plot of the nomalized data yield a single curve if it ignores void-void interaction? There seem to be only two possible conclusions which may be dramn:

1. Void-void interaction is unimportant and in no way affects the strength of a specimen.

2. Weibul1's analysis works, but fox the wrong reasons. 
The deviation of these data from Vardax's rigorous extension of Weibull's analysis seems to indicate that Weibull's analysis, at least in classical terms, may be incorrect. This contention is further strengthened by the fact that several investigators, including Batdorf, ${ }^{9}$ have found limitations in Weibul1's analysis. Furthermore, it would seem improbable that a flaw of such dimensions as a cluster of two or more voids would cause less reduction in strength (be a stronger link in the chain) than some intrinsic flaw which cannot be detected at present. This Iine of reasoning leads to the belier that conclusion 1 is not correct. What then is the explanation of the fact that Weibull's analysis has successiuly predicted data for nearly forty years and has predicted the nomalized data of this study so well? we have previously noted that Weibull statistics axe based on extreme value theory. Weibull assumed the statistical variation in the size of single flaws composed the change in flaw sevexity. Mcclintock took a different approach. He assuned that all single flaws were of approximately the same size (the length of one grain) and that the extreme value of these local single flaw densities leads to the most severe flaw. That is, the most severe flaw consists of $1,2,3, \ldots . n$ single flaws xandomly combined to form $a$ large flaw. In the case of externally produced voids a similar situation exists: local variation in void densities produce clusters of voids which may be considered as the large rlaw. As noted by Pankow, 19 Weibull and Mcclintock are compatible within the normal range of experimental data (volumes), thus it is not unxeasonable for our normalized data to fit Weibull statistics. It is the author"s opinion that 
Mcclintock's "simple and inexact model" of randomly combined single defects provides a sound explanation of the strength behavior of polycrystaline brittle solids. The fact that the Mcclintock model predicts forty years of data as well as does Weibull's analysis lends some credence to this opinion. 


\section{CONCLUSIONS}

In this study we have examined the effect of artificially introduced voids on the strength of a polycrystalline brittle solid. Traditional empirical and phenomenological strength-porosity relationships were found to correlate poorly with the data.

The most possible direct test of Weibull statistics using Vardar's analysis of the stress field produced by spherical voids indicated that these data did not follow Weibull statistics. Based on microstructural examination, Weibu1d's basic assumption of no flaw-flaw interaction was shown to be unacceptable in a system of randomly distributed rlaws. However, the composite Weibull plot of the normalized strength values indicated that the same flaw populations caused failure in most samples. Based on Mcclintock's model of randomly distributed cracked grain boundaries, the weakest link theory and microstructural evidence of clusters of voids, we propose that fluctuations in the local void densities produce clusters of voids which are the most critical flaws in the sample and are thus responsible for the noted reductions in strength with increasing void fractions. 


\section{ACKNONLEDGMENT}

I must express my sincere appreciation to Brofessor Joseph $A$. pask for his continued involvement and encouragement during the course of this woxk. Fuxther thanks must be given to Iain Finnie and David Pankow for their worthwhile technical input. I also wish to mention those who not only became technical advisors but also friends Richard M. Fulrath, Bob R. Powell, Jr., Dipak R. Biswas and Hans Eckart Exner. Many others should be included in any mention of those who have made the last two years at Berkeley so enjoyable and worthwhile but the space is too short for a complete list; those people, students and 1 ab pexsonnel, must be content with the fact that I treasure these two years of my life and will never forget them. Finally, mention must be made of those who provided a warm and loving atmosphere away from the lab - my parents, Mr. and Mrs. A. G. Wallace, and Gwen Tatsuno. This work was supported by the Division of Materials Sciences. Office of Basic Energy Sciences, U.S. Department of Energy. 
Table I

\begin{tabular}{|c|c|c|c|c|c|c|c|}
\hline $\begin{array}{c}\text { Mean } \\
\text { void } \\
\text { aimeter } \\
\text { d. m }\end{array}$ & $\begin{array}{c}\text { Volume } \\
\text { Eraction } \\
\text { voids. } \\
{ }_{V}\end{array}$ & $\begin{array}{l}\text { Mean } \\
\text { strength } \\
S_{\text {TS }} \text { MPa }\end{array}$ & $\begin{array}{l}\text { Coefficient } \\
\text { of variation } \\
\mathrm{CV}\left(\mathrm{S}_{\mathrm{o}} / \mathrm{S}_{\mathrm{TS}}\right)\end{array}$ & $\begin{array}{l}\text { Median } \\
\text { strength } \\
S_{\text {wS }} \text { MPa }\end{array}$ & $\begin{array}{c}\text { Characteristic } \\
\text { strength } \\
S_{0}, M P a\end{array}$ & $\begin{array}{l}\text { Weibu11 } \\
\text { modulus. } \\
\text { m }\end{array}$ & $\begin{array}{c}\text { Number } \\
\text { of } \\
\text { specimens }\end{array}$ \\
\hline \multirow[t]{2}{*}{-} & 0 & 300 & 0.061 & 310 & 230 & 16.3 & 11 \\
\hline & .012 & 270 & 0.073 & 275 & 195 & 12.7 & 9 \\
\hline \multirow[t]{5}{*}{28} & .022 & 255 & 0.037 & 260 & 210 & 26.6 & 12 \\
\hline & .034 & 230 & 0.067 & 225 & 175 & 15.1 & 12 \\
\hline & .018 & 240 & 0.034 & 240 & 200 & 28.6 & 12 \\
\hline & .037 & 235 & 0.043 & 240 & 190 & 23.3 & 13 \\
\hline & .039 & 235 & 0.029 & 230 & 195 & 34.2 & 11 \\
\hline \multirow[t]{6}{*}{48} & .059 & 205 & 0.052 & 205 & 160 & 20.0 & 12 \\
\hline & .072 & 210 & 0.047 & 210 & 165 & 20.2 & 9 \\
\hline & .116 & 175 & 0.043 & 175 & 140 & 22.7 & 12 \\
\hline & .017 & 225 & 0.040 & 225 & 180 & 24.2 & 10 \\
\hline & .036 & 215 & 0.053 & 220 & 170 & 19.7 & 13 \\
\hline & .038 & 210 & 0.058 & 205 & 160 & 16.5 & 12 \\
\hline \multirow[t]{4}{*}{80} & .064 & 190 & 0.037 & 190 & 155 & 26.8 & 12 \\
\hline & .071 & 195 & 0.059 & 195 & 150 & 17.6 & 13 \\
\hline & .115 & 155 & 0.050 & 155 & 120 & 18.6 & 12 \\
\hline & & & $\bar{x}=0.048$ & & & $\bar{y}=20.6$ & $\Sigma=198$ \\
\hline
\end{tabular}


APPENDIX 1

Refer to Fig. 3. $1 \mathrm{~b}$

$$
\begin{aligned}
& \text { Increasing moment } \\
& \text { end region } \\
& \text { Constant moment } \\
& \text { centex region } \\
& \sigma(x, y)=S_{T S}\left(\frac{x}{\ell / 2}\right)\left(\frac{y}{h / 2}\right) \\
& \sigma(x, y)=S_{T S}\left(\frac{y}{h / 2}\right) \\
& =S_{\operatorname{TS}} \frac{\frac{\Delta x y}{2}}{l_{2} h} \\
& =S_{T S}\left(\frac{2 y}{h}\right) \\
& B_{1}=2 \int_{V} g(S) d V=2 \int_{V}\left(\frac{\sigma(x, y)}{s_{0}}\right)^{m} d V \quad B_{2}=\int_{V} g(S) d V=\int_{V} \frac{s_{T S}}{S_{0}}\left(\frac{y}{h / 2}\right) d V \\
& B_{1}=2 w \int_{0}^{h / 2} \int_{0}^{\ell_{2} / 2}\left[\frac{S_{\mathrm{TS}}}{S_{0}}\left(\frac{4 x y}{l_{2} h}\right)\right]^{\mathrm{m}} \mathrm{dxdy} \mathrm{B}_{2}=w_{1} \int_{0}^{h / 2}\left(\frac{S_{\mathrm{TS}}}{S_{0}}\left(\frac{y}{h / 2}\right)\right)^{\mathrm{M}} d y \\
& B_{1}=\frac{2 w}{(m+1)^{2}}\left(\frac{l^{2} h}{4}\right)\left(\frac{S_{S}}{S_{0}}\right)^{m} \\
& B_{2}=l_{1} w\left(\frac{S_{T S}}{S_{0}}\right)^{m}\left(\frac{h / 2}{m+1}\right) \\
& B_{1}=\frac{\text { wh } \ell_{2}}{2(m+1)^{2}}\left(\frac{S_{T S}}{S_{0}}\right)^{m} \\
& B_{2}=\frac{\ell_{1} w h}{2(m+1)}\left(\frac{S_{\text {TS }}}{S_{0}}\right)^{m} \\
& B=B_{1}+B_{2} \\
& B=\left[\frac{w h l_{2}}{2(m+1)^{2}}+\frac{l_{1}}{2(m+1)}\right]\left(\frac{S_{S S}}{S_{0}}\right)^{n} \\
& B=\frac{w h}{2(m+1)}\left[l_{1}+\frac{\ell_{2}}{m+1}\right]\left(\frac{S_{5}}{S_{0}}\right)^{m}
\end{aligned}
$$
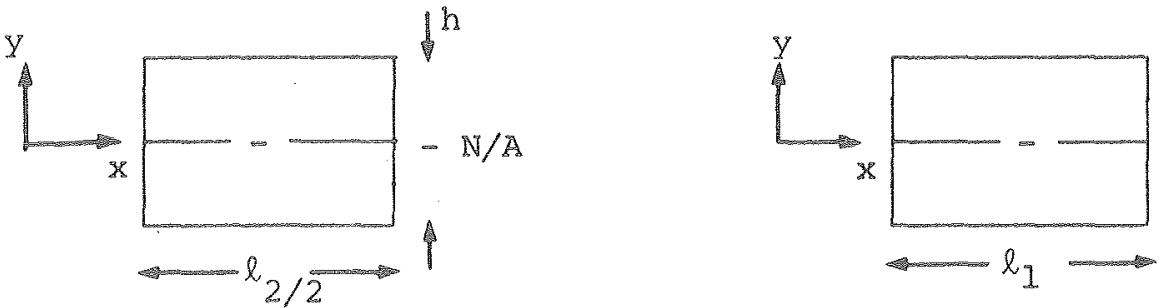
REFERENCES

1. O. Vardar, I. Finnie, D. R. Biswas and R.M. Fulrath, Efect of Sphexical Pores on the Strength of Polycrystaline Cexamic, Int. J. Fracture 13(2), 215 (1977).

2. J. N. Goodiex, Concentration of Stress Around Spherical and Cylindrica1 Inclusions and Flaws, J. App1. Mech. I(1), 39-44 (1933).

3. F. A. McClintock, Statistics of Brittle Fracture, Fracture Mechanics of Ceramics I, Plenum Press, N.Y. (1974), P. 93.

4. R.W. Rice, Fxactographic Identification of Strength-Controlling Flaws and Microstructure, ibia, p. 323.

5. O. L. Bowie, J. Math and Phys. 35, 66-71 (1956).

6. A. G. Evans and T. G. Langdon, Structural Cexamics, Prog. in Mat1. Sci. Vo1.21, Pergamon Press (1976).

7. H. A. Neid and Ko Arin. Multiple Flaw Fracture Mechanics Model for Cexanics, Presented at the International Symposium on Fracture Mechanic of Ceramics, July $27-29,1977$.

8. W. T. Koitex, Ingen,Evx ARCK, 28, 168-72 (1959).

9. S. B. Batdorf, Fracture Statistics of Brittle Materials, Nuc. Eng. Des. 35, 349-60 (1975).

10. F. I. Baratta, Stress Intensity Estimates of a Pexipherallycracked Spherical Void and a Hermisphexical Surface Pit, Presented at the Amexican Ceramics Society Annual Meeting, 1978.

11. Amexican Society for Testing and Materials STP 381 (1965).

12. A. G. Evans and G. Tappin, The Effects of Microstructure on the Stress to Propagate Inherent Flaws, Proc. Brit. Ceram. Soc. N20 275-97(1972). 
13. G. C. Sih, Handbook of Stress Intensity Factors, Inst. Fracture and Solid Mech. Lehiglt Univ. (1973).

14. M. Tada, The Stress Analysis of Cracks Handbook, Del Research (1973)。

15. D. Nk. Wang, (Ph.D. thesis), University of California, Bexkeley (1976)。

16. Underwood, Quantative Stereology, Addison-Wesley, 1970.

17. J. S. Wallace, unpublished Research

18. R. W. Rice, Fractographic Identification of Strength Controlling Flaws and Microstructure, Fracture Mechanics of Ceranics V1.

19. D. Pankow, The Size Effect in Statistical Fracture, Ph.D. thesis, University of California. Berkeley

20. A. Salak, V. Miskovic, E. Dudrova and E. Rudnayova, The Dependence of Mechanical Properties of Sintered Iron Compacts Upon Porosity, Powd. Met. Int. 6, (2) (1974).

21. I. Finnie, Mechanical Engineexing 225B Course Notes, Fall 1976.

22. D. R. Biswas, The Influence of Porosity on the Mechanical Properties of Lead-Zirconate-Titanate Ceramics, Bh.D. thesis, University of California, Berkeley, (1976).

23. I. Finnie, D. Pankow (private communications).

24. R. L. Coble and N. M. Parikit, Fracture of Polycrystaline Ceramics, in Fracture V8 edited by

25. W. D. Kingery, H. K. Bowen and D. R. OhImann, Introduction to Cexamics, John wiley \& Sons, 1976. 
NOMENCTATURE

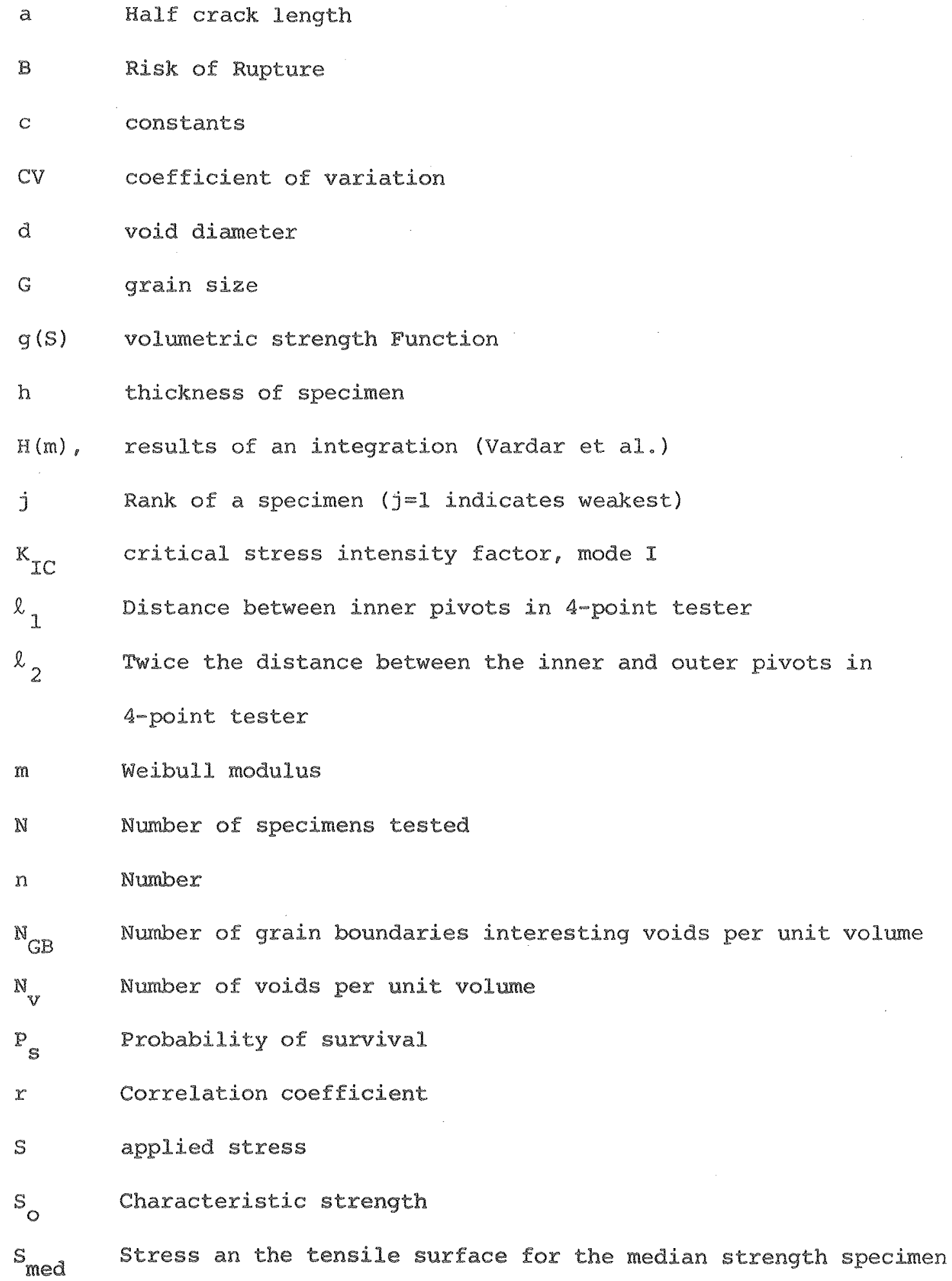




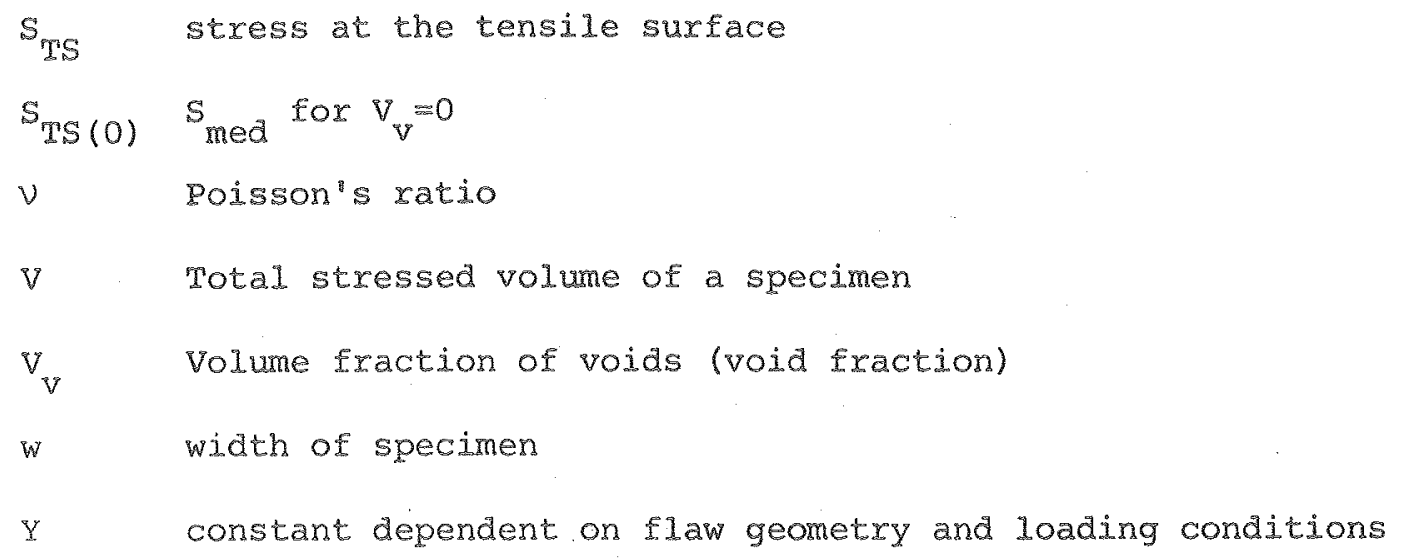


This report was done with support from the Department of Energy. Any conclusions or opinions expressed in this report represent solely those of the author(s) and not necessarily those of The Regents of the University of California, the Iawrence Berkeley Laboratory or the Department of linergy. 


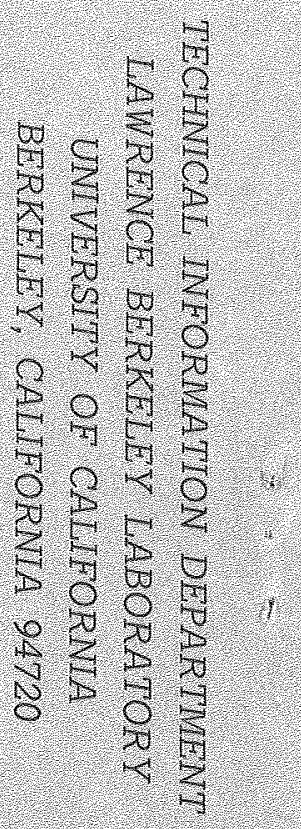

